\title{
On the structural origin of free volume in 1-alkyl-3-methylimidazolium ionic liquid mixtures: a SAXS and ${ }^{129}$ Xe NMR study
}

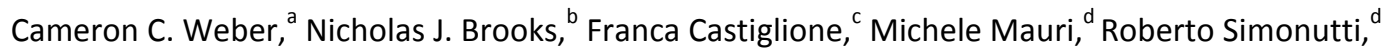 \\ Andrea Mele, ${ }^{\text {cee }}$ and Tom Welton* ${ }^{\text {b }}$
}

a. School of Science, Auckland University of Technology, Auckland (New Zealand).
b. Department of Chemistry, Imperial College London, London, SW7 2AZ (UK).
c. Dept Chemistry, Materials and Chemical Engineering "G. Natta"-Politecnico di Milano (Italy).
d. Dipartimento di Scienza dei Materiali, Università of Milano-Bicocca, Milano (Italy).
e. CNR-ICRM Istituto di Chimica del Riconoscimento Molecolare, Milano (Italy).

\begin{abstract}
Ionic liquid (IL) mixtures enable the design of fluids with finely tuned structural and physicochemical properties for myriad applications. In order to rationally develop and design IL mixtures with the desired properties, a thorough understanding of the structural origins of their physicochemical properties and the thermodynamics of mixing needs to be developed. To elucidate the structural origins of the excess molar volume within ionic liquid (IL) mixtures containing ions with different alkyl chain lengths, 3 IL mixtures containing 1-alkyl-3-methylimidazolium bis(trifluoromethanesulfonyl)imide ILs have been explored in a joint small angle Xray scattering (SAXS) and ${ }^{129}$ Xe NMR study. The apolar domains of the IL mixtures were shown to possess similar dimensions to the largest alkyl chain of the mixture with the size evolution determined by whether the shorter alkyl chain was able to interact with the apolar domain. ${ }^{129}$ Xe NMR results illustrated that the origin of excess molar volume in these mixtures was due to fluctuations within these apolar domains arising from alkyl chain mismatch, with the formation of a greater number of smaller voids within the IL structure. These results indicate that free volume effects for these types of mixtures can be predicted from simple considerations of IL structure and that the structural basis for the formation of excess molar volume in these mixtures is substantially different to IL mixtures formed of different types of ions.
\end{abstract}

\section{Introduction}

Ionic liquids (ILs) are low melting salts. ${ }^{1}$ ILs have been explored for numerous applications as solvents and materials, ${ }^{2-4}$ including as reaction solvents, ${ }^{1,5,6}$ for separations and purifications including biomass processing ${ }^{7-9}$ and as materials for energy production and storage. ${ }^{10,11}$ of particular interest has been the possibility of tuning the physicochemical properties of ILs through the appropriate selection of ions to tailor the IL for the desired application. ${ }^{12,13}$ The limitation of this approach is that the physicochemical and toxicological properties of every new IL are not yet able to predicted with a high degree of accuracy and regulatory requirements associated with the development of new substances limit their scope for industrial applications. An alternative proposal has been the development of IL mixtures which allows the use of known ILs that are fully characterised to prepare liquids that have the desired physicochemical properties. ${ }^{12,14}$ To enable the more widespread application of IL mixtures, the impact of mixing ILs on their structures and physicochemical properties needs to be thoroughly understood.

We, and others, have recently investigated the thermodynamics of mixing ILs that contain different cation and anion types as well as the effect of mixing on their structures and resultant physicochemical properties. ${ }^{12,}{ }^{14-26}$ These results indicate that most IL mixtures display close to ideal mixing behaviour with deviations occurring primarily when ion sizes are significantly mismatched or there is a difference in the strength and orientation of electrostatic interactions. ${ }^{22,23,27}$ While the understanding of the impact of mixing different types of ions has developed substantially over the past few years, relatively few studies have focused on the effect of mixing ILs containing similar ions that differ only in the length of the alkyl chain. ${ }^{28-35}$ Further, the precise structural origin of excess thermodynamic properties and the evolution of physicochemical properties for these types of mixtures has not been elucidated.

The major impact of the length of the alkyl chain on IL structure relates to the formation of amphiphilic nanostructure. If the IL alkyl chains are sufficiently long, they are excluded from interacting with the polar ionic network leading to their aggregation and the formation of a well-defined apolar domain. ${ }^{36-38}$ For the homologous series of 1-alkyl-3methylimidazolium bis(trifluoromethanesulfonyl)imide ILs $\left(\left[\mathrm{C}_{n} \mathrm{C}_{1} \mathrm{im}\right]\left[\mathrm{NTf}_{2}\right]\right)$, small angle X-ray scattering (SAXS) data suggests that amphiphilic nanostructure begins to form when $n \geq 3 .^{39}$ Optical Kerr effect spectroscopy and molecular dynamics (MD) simulations indicate that alkyl chain aggregates begin to form but they are not continuous throughout the 
IL structure for small values of $n$ such as $3 \leq n \leq 5$, whereas bicontinuous polar and apolar domains exist at longer alkyl chain lengths. ${ }^{40}$ The amphiphilic nanostructure of ILs has been implicated in effects on reaction rates and stereoselectivity, ${ }^{2,41-44}$ as well as the preparation of inorganic materials and nanomaterials. ${ }^{45-49}$ This highlights the importance of understanding the existence and evolution of this structural feature.

SAXS techniques have been widely used to examine the amphiphilic nanostructure of ILs. Three main peaks are commonly observed in the SAXS patterns of aprotic ILs, which have been assigned to specific correlations based on molecular dynamics (MD) simulations of experimental SAXS data. ${ }^{39}, 50-52$ Peak I corresponds to the correlation distance along the axis of the alkyl chain and peak II primarily to the anion-anion repeat distance within the polar network. Peak III is generally linked to intramolecular correlations and the cation-anion alternation distance. Given the large number of underlying structural effects contributing to peak III and the experimental issues highlighted in the experimental section, we will not discuss peak III for the mixtures examined here. The correlations giving rise to peaks I, II and III are depicted in an 'idealised' fashion in Figure 1.

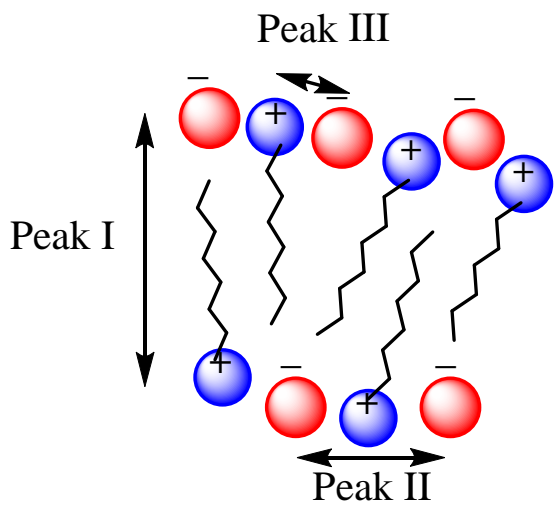

Figure 1. Idealised schematic illustrating the three main correlation peaks observed using SAXS. ${ }^{23}$

The effect of forming IL mixtures on the amphiphilic nanostructure of ILs has recently been explored. For $\left[C_{1} C_{1} i m\right]_{x}\left[C_{12} C_{1} i m\right]_{1-x}\left[N T f_{2}\right]$ and $\left[C_{2} C_{1} i m\right]_{x}\left[C_{12} C_{1} i m\right]_{1-x}\left[N T f_{2}\right]$, where an IL that does not possess amphiphilic nanostructure is combined with one that does, it was found that isolated prolate micelle-like aggregates of $\left[\mathrm{C}_{12} \mathrm{C}_{1} \mathrm{im}\right]\left[\mathrm{NTf} \mathrm{f}_{2}\right]$ form at low concentrations which coalesce with increasing $\left[\mathrm{C}_{12} \mathrm{C}_{1}\right.$ im] $\left[\mathrm{NTf}_{2}\right]$ concentration to form bicontinuous nanostructures. ${ }^{33-35}$ As the $\left[\mathrm{C}_{12} \mathrm{C}_{1}\right.$ im] $\left[\mathrm{NTf}_{2}\right]$ concentration decreased, a net increase in the observed polar-apolar correlation distance, as determined by the position of peak 1 , and decrease in intensity of this peak was observed using SAXS techniques. A combined experimental and MD study of the effect of dissolving lithium nitrate in alkylammonium nitrate ILs on the nanostructure of the IL yielded similar trends with a gradual increase in polar-apolar correlation distance as the lithium nitrate concentration increased. ${ }^{53}$ This was attributed to the lithium salt disrupting the hydrogen bonding network and introducing orientational disorder within the polar domains. In contrast, MD simulations of the structure of $\left[\mathrm{C}_{2} \mathrm{C}_{1} \mathrm{im}\right]_{0.50}\left[\mathrm{C}_{6} \mathrm{C}_{1} \mathrm{im}\right]_{0.50}\left[\mathrm{NTf}_{2}\right]$ suggested that similar structural organisation is observed in this mixture as in $\left[\mathrm{C}_{4} \mathrm{C}_{1} \mathrm{im}\right]\left[\mathrm{NTf} \mathrm{f}_{2}\right]$, which would have a similar alkyl chain volume, rather than the formation of isolated $\left[\mathrm{C}_{6} \mathrm{C}_{1} \mathrm{im}_{[\mathrm{NTf}}\right]$ aggregates or an increase in the size of the polar domain of $\left[\mathrm{C}_{6} \mathrm{C}_{1} \mathrm{im}\right]\left[\mathrm{NTf} \mathrm{f}_{2}\right]{ }^{54}$ The latter result may indicate that the ability to form aggregates rather than interdigitated bicontinuous structures relates to the extent of alkyl chain mismatch as well as the structures of the simple ILs.

The effect on the nanostructure of mixtures of ILs that both contain amphiphilic nanostructures has been examined for $\left[\mathrm{C}_{6} \mathrm{C}_{1} \mathrm{im}\right]_{x}\left[\mathrm{C}_{10} \mathrm{C}_{1} \mathrm{im}\right]_{1-\mathrm{x}} \mathrm{Cl}$ mixtures. ${ }^{31}$ It was found that the alkyl chains of both cations mixed rather than forming individual $\mathrm{IL}$ aggregates of the type observed in the $\left[\mathrm{C}_{1} \mathrm{C}_{1} \mathrm{im}\right]_{x}\left[\mathrm{C}_{12} \mathrm{C}_{1} \mathrm{im}\right]_{1-x}\left[\mathrm{NTf}_{2}\right]$ mixtures. While the size of the apolar domains decreased with increasing $\left[\mathrm{C}_{6} \mathrm{C}_{1} \mathrm{im}\right] \mathrm{Cl}$ concentration, the change was non-linear with larger apolar domain sizes relative to a linear interpolation between the simple ILs. This likely arises from a mismatch in alkyl chain sizes with the larger decyl chains limiting the ability of the apolar domains to contract in the presence of the shorter hexyl chains.

The thermodynamics of mixing of ILs that differ only in the length of their alkyl chain have been studied and in general exhibit only relatively small deviations from ideality. $\left[C_{n} C_{1} i m\right]_{x}\left[C_{m} C_{1} i m\right]_{1-x}\left[N T f_{2}\right]$ IL mixtures, where $n$ and $m$ were even values from 2-10, were found to be non-ideal, based on the observation of positive excess volumes. ${ }^{28}$ The magnitude of the excess volume increased with the difference in the size of the alkyl chain of the two cations, albeit all values remained small in magnitude. The reduced excess volumes, i.e. the excess volume divided by the molar volume of the mixture, 
agreed with those determined for mixtures of alcohols with similar differences in alkyl chain length. Similar deviations from ideality, as determined by excess molar volumes, have also been observed for $\left[C_{2} C_{1} i m\right]_{x}\left[C_{12} C_{1} i_{m}\right]_{1-x}\left[N T f_{2}\right]$ mixtures. ${ }^{34}$

The thermodynamics of mixing of ILs featuring cations with different alkyl chain lengths has also been explored using calorimetry measurements. ${ }^{55-57}$ The calorimetry measurements identified small positive $\Delta_{\text {mix }} \mathrm{H}$ for these mixtures, with the magnitude of $\Delta_{\text {mix }} \mathrm{H}$ increasing with the difference in alkyl chain length for imidazolium ILs containing both the [BF $]^{-}$and $\left[\mathrm{NTf}_{2}\right]^{-}$anions. However, the largest $\Delta_{\text {mix }} \mathrm{H}$ observed at an equimolar mixture was only $0.359 \mathrm{~kJ} \mathrm{~mol}^{-1}$ for the $\left[\mathrm{C}_{4} \mathrm{C}_{1} \mathrm{im}\right]_{x}\left[\mathrm{C}_{10} \mathrm{C}_{1} \mathrm{im}\right]_{1-\mathrm{x}}\left[\mathrm{NTf}_{2}\right]$ mixture, illustrating the relatively small deviations from ideality. An unanswered question as a result of these studies has been how does the evolution of amphiphilic nanostructure affect the thermodynamics of mixing and physicochemical properties of the resultant mixture? The precise structural origin of these excess properties also remains unresolved.

${ }^{129} \mathrm{Xe}$ NMR has been used for the characterisation of the free volume of condensed phases such as porous solids, molecular liquids and ILs. ${ }^{23,58-66}$ Xe can occupy cavities within a liquid that are sufficiently large to accommodate the Xe atom (Xe hard core radius $r=3.89 \AA$; van der Waals radius $r_{X e}=2.16 \AA$ ). The chemical shift of Xe in a condensed phase has been found to depend on the sum of three factors: the interaction of Xe with the wall of the cavity, the interaction of Xe with other Xe atoms, and the polarisation of Xe in response to electrical fields, in this case induced by the fragment of the IL that comprises the wall of the cavity. ${ }^{59,67}$ These factors comprise the overall chemical shift observed in accordance with Eq. 1 where $\rho$ is the density of the gas, $\delta_{0}$ is the reference chemical shift, $\delta_{\text {wall }}$ is the chemical shift caused by the wall of the cavity, $\delta_{\mathrm{Xe}-\mathrm{Xe}}$ is the chemical shift caused by Xe-Xe interactions and $\delta_{\mathrm{E}}$ is the chemical shift contribution due to polarisation.

$$
\delta=\delta_{0}+\delta_{\text {wall }}+\delta_{X e-X e} \rho+\delta_{E}
$$

In ILs, the change in ${ }^{129} \mathrm{Xe}$ chemical shift has been associated with changes in the nature of the anion and the alkyl chain for imidazolium ILs. ${ }^{23,65,66,68,69}$ In general, as the length of the alkyl chain increases, the Xe atom is preferentially oriented near the alkyl chain region of the IL and excluded from the polar region near the imidazolium ring. ${ }^{66,68,69}$ For

$\left[\mathrm{C}_{n} \mathrm{C}_{1} \mathrm{im}\right]\left[\mathrm{NTf}_{2}\right]$ ILs this has a net effect of increasing the observed Xe chemical shift as van der Waals interactions with the alkyl chains are more deshielding than those with the polar regions of these ILs. The opposite trend is observed for ILs with halide anions due to the increased polarisation of Xe induced by these anions. Within a set of IL mixtures, the excess ${ }^{129}$ Xe NMR chemical shift $\left(\delta^{\mathrm{E}}\right)$ has been found to correlate well with the excess molar volume $\left(\mathrm{V}^{\mathrm{E}}\right)$ and free volume of the mixtures hence under these circumstances it is able to act as a thermodynamic as well as structural probe. ${ }^{23}$ Given the relationship between free volume and physicochemical properties such as viscosity, conductivity, glass transitions and gas solubility, ${ }^{70-74}{ }^{129}$ Xe NMR can provide insight that links the structure and physicochemical properties of IL mixtures.

Here, we examine the relationship between the amphiphilic nanostructure, ${ }^{129} \mathrm{Xe} N \mathrm{NM}$ chemical shift and excess molar volumes of a set of three IL mixtures featuring $\left[C_{n} C_{1} i m\right]\left[N T f_{2}\right]$ ILs. The three mixtures, $\left[C_{2} C_{1} i m\right]_{x}\left[C_{10} C_{1} i m\right]_{1-x}\left[N T f_{2}\right]$, $\left[\mathrm{C}_{4} \mathrm{C}_{1} \mathrm{im}\right]_{x}\left[\mathrm{C}_{10} \mathrm{C}_{1} \mathrm{im}\right]_{1-\mathrm{x}}\left[\mathrm{NTf} \mathrm{f}_{2}\right]$ and $\left[\mathrm{C}_{4} \mathrm{C}_{1} \mathrm{im}\right]_{x}\left[\mathrm{C}_{6} \mathrm{C}_{1} \mathrm{im}\right]_{1-\mathrm{x}}\left[\mathrm{NTf} \mathrm{f}_{2}\right]$ were chosen to include the mixing of an IL without an amphiphilic nanostructure and one that does, the mixing of two ILs with amphiphilic nanostructures but significantly different alkyl chains lengths and those that possess amphiphilic nanostructure but have similar alkyl chain lengths. The aim of these studies was to isolate whether the existence or nature of the amphiphilic nanostructure is of significance for the formation of excess free volume within these mixtures and consequently to determine the structural origins of excess free volume formation given its importance for understanding the physicochemical properties and thermodynamics of these mixtures.

\section{Experimental}

\section{Density Measurements}

Density measurements were performed in an Anton Paar 'DMA 38' vibrating tube density meter at $298 \mathrm{~K}$ with a stated accuracy of $\pm 0.001 \mathrm{~g} \mathrm{~mL}^{-1}$. The density meter was calibrated using degassed distilled water and the accuracy was intermittently monitored by the use of degassed distilled water as a standard. Prior to each measurement, 'dry' IL samples were further dried at $323 \mathrm{~K}$ for at least $16 \mathrm{~h}$. All density measurements were obtained in triplicate to ensure reproducibility. Reproducibility was found to be $\pm 0.0001 \mathrm{~g} \mathrm{~mL}^{-1}$.

\section{Small angle $\mathrm{X}$-ray scattering experiments}

Samples for X-ray scattering experiments were loaded into $1.5 \mathrm{~mm}$ thin-walled special glass X-ray capillary tubes (Capillary Tube Supplies, Reading, UK). Scattering experiments were carried out on beamline 122 at Diamond Light source with an X-ray energy of $17 \mathrm{keV}$ (wavelength of $0.73 \AA$ ) and a sample to detector distance of $1.2 \mathrm{~m}$ giving access to $\mathrm{S}$ of 
0.004 to $0.20 \AA^{-1}(S=1 / d)$ on the SAXS camera. A WAXS detector was also employed, giving access to $S$ up to $1.28 \AA^{-1}$. 2D scattering patterns were recorded using a Pilatus $2 \mathrm{M}$ detector and silver behenate (which has a well-defined lattice parameter of $58.38 \AA$ ) was used to calibrate all X-ray scattering data. The temperature of the capillaries was maintained at $25{ }^{\circ} \mathrm{C}$ through the use of a water recirculator fitted to the capillary holder, with the temperature determined by a thermocouple inserted into the capillary holder. The scattering images were integrated to give 1D scattering plots using custom software developed in National Instruments LabVIEW. The position and shape of the scattering peaks were analysed using the Origin data analysis package. Scattering profiles were fitted to three Pearson VII profiles corresponding to Peak I, Peak II and Peak III (vide infra).

Unfortunately, the WAXS detector was not functioning correctly on one occasion leading to no data collection in the $\mathrm{S}>$ $0.20 \AA^{-1}$ region. This enabled only the first two peaks to be resolved. Fitting Pearson VII profiles to Peaks I and II with a sloping baseline was able to account for tailing effects arising from Peak III, giving results consistent with the three peak fit within experimental error. The remainder of the data analysis was performed as described above.

\section{${ }^{129}$ Xe NMR spectroscopy}

Sealed NMR tubes containing ILs and xenon gas were prepared as follows. Each IL sample was thoroughly degassed directly within its NMR tube by several freeze-thaw cycles under dynamic vacuum $\left(8 \times 10^{-2}\right.$ torr $)$ provided by a Schlenk manifold as depicted in ESI. Upon thawing, the liquid initially displayed extensive bubbling and foaming, which disappeared after up to 15 separate cycles. After that, since ILs do not present any detectable evaporation phenomena at room temperature, we left them overnight in dynamic vacuum to remove any residual gas traces.

Xe gas was inserted into a section of the manifold with known volume, to allow its quantitation and then allowed in the NMR tube. The gas was frozen there with liquid nitrogen, and finally each tube was flame sealed, upon verifying that the sealing region was free from IL droplets that could decompose and contaminate the sample. Each tube was then brought slowly back to room temperature.

Considering the size of the NMR tubes, (around $120 \mathrm{~mm}$ effective height, $5 \mathrm{~mm}$ external diameter, $0.38 \mathrm{~mm}$ walls, 4.25 $\mathrm{mm}$ internal diameter) and the amount of sample $(300 \mu \mathrm{L})$, as well as the volume of all the manifold elements involved, a pressure of 170 torr within the manifold corresponded to $3.5 \mathrm{~atm}$ within the tube. Note that this nominal pressure does not consider the substantial amount of Xe adsorbed by the IL.

The ${ }^{129}$ Xe NMR spectra were collected on a Bruker DRX 500 high-resolution spectrometer operating at ${ }^{129}$ Xe frequency of 138.302 $\mathrm{MHz}$ (corresponding to $499.60 \mathrm{MHz}$ for ${ }^{1} \mathrm{H}$ ) and equipped with a $5 \mathrm{~mm}$ broadband inverse probehead. Typical settings: 1024 scans, $50 \mathrm{~s}$ relaxation delay, $710 \mathrm{ppm}$ spectral width. ${ }^{129}$ Xe spectra were referenced utilising the approach of Lim and King, ${ }^{63}$ with a center band frequency of $138.2076 \mathrm{MHz}$ employed for all measurements. ${ }^{129}$ Xe chemical shifts were referenced by setting the value for Xe dissolved in benzene to $188.1 \mathrm{ppm} .{ }^{75}$ All the experiments were carried out at $25^{\circ} \mathrm{C}$. The temperature calibration was done by using methanol as a reference standard.

\section{Results and Discussion}

\section{Small angle X-ray scattering experiments}

SAXS patterns were obtained for the $\left[\mathrm{C}_{2} \mathrm{C}_{1} \mathrm{im}\right]_{\times}\left[\mathrm{C}_{10} \mathrm{C}_{1} \mathrm{im}\right]_{1-\mathrm{x}}\left[\mathrm{NTf} \mathrm{f}_{2}\right],\left[\mathrm{C}_{4} \mathrm{C}_{1} \mathrm{im}\right]_{\times}\left[\mathrm{C}_{10} \mathrm{C}_{1} \mathrm{im}\right]_{1-\mathrm{x}}\left[\mathrm{NTf}_{2}\right]$ and $\left[\mathrm{C}_{4} \mathrm{C}_{1} \mathrm{im}\right]_{\times}\left[\mathrm{C}_{6} \mathrm{C}_{1} \mathrm{im}\right]_{1-\mathrm{x}}\left[\mathrm{NTf} \mathrm{f}_{2}\right]$ mixtures to elucidate the effect of forming these mixtures on their structure. These patterns are displayed in Figure 2.
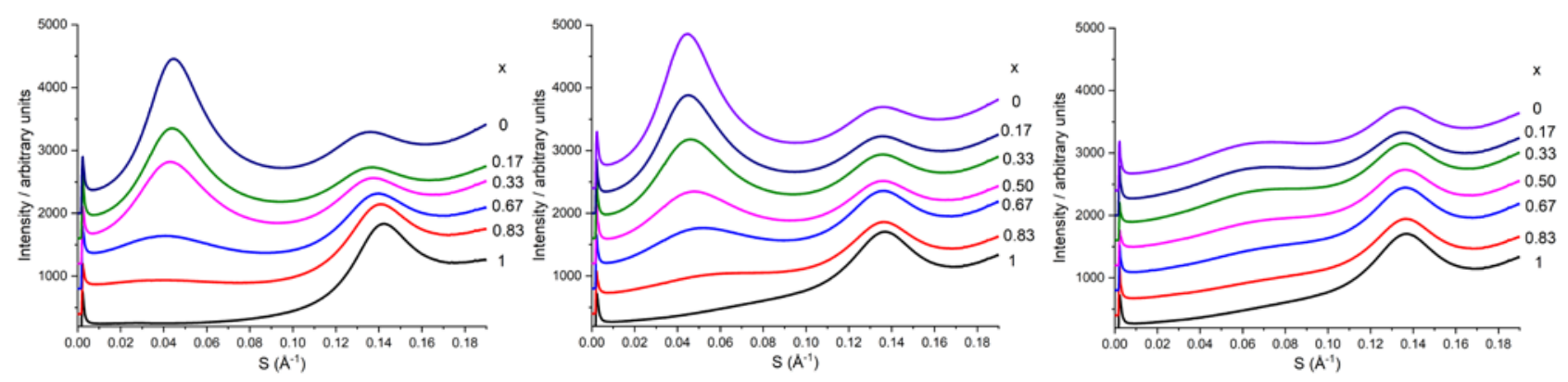

Figure 2. SAXS patterns for (left to right): $\left[\mathrm{C}_{2} \mathrm{C}_{1} \mathrm{im}\right]_{\times}\left[\mathrm{C}_{10} \mathrm{C}_{1} \mathrm{im}\right]_{1-\mathrm{x}}\left[\mathrm{NTf} \mathrm{f}_{2}\right],\left[\mathrm{C}_{4} \mathrm{C}_{1} \mathrm{im}\right]_{\times}\left[\mathrm{C}_{10} \mathrm{C}_{1} \mathrm{im}\right]_{1-\mathrm{x}}\left[\mathrm{NTf}_{2}\right]$ and $\left[\mathrm{C}_{4} \mathrm{C}_{1} \mathrm{im}_{\times}\left[\mathrm{C}_{6} \mathrm{C}_{1} \text { im }\right]_{1-\mathrm{x}}\left[\mathrm{NTf} \mathrm{f}_{2}\right]\right.$ mixtures.

From examining the SAXS patterns, it is evident that the intensity of peak I varies greatly across these mixtures with the intensity the greatest for $\left[\mathrm{C}_{10} \mathrm{C}_{1} \mathrm{im}\right]\left[\mathrm{NTf}_{2}\right]$ and mixtures with a high proportion of this IL. This is unsurprising given peak I corresponds to the order that arises from the formation of an apolar domain, which occurs more readily for ILs with longer alkyl chains, an effect that 
has been observed previously for similar mixtures. ${ }^{34,35}$ Peak I is even observed for the $\left[\mathrm{C}_{2} \mathrm{C}_{1} \mathrm{im}_{0.83}\left[\mathrm{C}_{10} \mathrm{C}_{1} \text { im }\right]_{0.17}\left[\mathrm{NTf} \mathrm{f}_{2}\right]\right.$ mixture, despite $\left[\mathrm{C}_{2} \mathrm{C}_{1}\right.$ im] $\left[\mathrm{NTf}_{2}\right]$ not forming apolar domains in the simple IL. This indicates the formation of apolar aggregates occurs even with only $17 \mathrm{~mol} \%\left[\mathrm{C}_{10} \mathrm{C}_{1}\right.$ im] $\left[\mathrm{NTf}_{2}\right]$ in the mixture. The breadth of this peak suggests that at this low concentration of $\left[\mathrm{C}_{10} \mathrm{C}_{1} \mathrm{im}\right]\left[\mathrm{NTf}_{2}\right]$ there are contributions from aggregates of differing sizes rather than the formation of bicontinuous polar and apolar domains. As the concentration of $\left[\mathrm{C}_{10} \mathrm{C}_{1} \mathrm{im}\right]\left[\mathrm{NTf}_{2}\right]$ increases, the peak narrows and becomes more well-defined which is indicative of the formation of bicontinuous polar and apolar domains for mixtures with $\mathrm{x}<0.67$.

For the $\left[\mathrm{C}_{4} \mathrm{C}_{1} \mathrm{im}\right]_{x}\left[\mathrm{C}_{10} \mathrm{C}_{1} \mathrm{im}\right]_{1-\mathrm{x}}\left[\mathrm{NTf} \mathrm{f}_{2}\right]$ mixtures a similar trend in terms of the intensity of peak $\mathrm{I}$ is observed with slightly increased intensity at each mixture composition. For the $\left[C_{4} C_{1} i m\right]_{x}\left[C_{6} C_{1} i m\right]_{1-x}\left[N T f_{2}\right]$ mixtures a broad peak $I$ is observed for all values of $x$ which indicates that even in the simple $\left[\mathrm{C}_{6} \mathrm{C}_{1} \mathrm{im}\right]\left[\mathrm{NTf}_{2}\right]$ there is a tendency to form smaller, less well-defined aggregates rather than a percolating polar and apolar network. This is consistent with the findings of MD simulations of this IL. ${ }^{54}$ In every case there is no evidence for the formation of multiple low $\mathrm{S}$ peaks which indicates that the apolar regions of both IL cations mix where this is possible rather than the formation of isolated aggregates of each cation.

Peak positions were obtained by fitting the peaks in the SAXS scatterplot to a Pearson's VII peak shape with details provided in the experimental section. The $S$ values obtained from this fit were transformed into correlation distances using the relationship $d=1 / S$. The experimental error for correlation distances for peak I is approximately $\pm 0.5 \AA$ based on replicate samples whereas for peak II it is approximately $\pm 0.05 \AA$. The resultant correlation distances are depicted in Figures 3 and 4 and are tabulated in Tables S2 and $\mathrm{S} 3$ in the ESI.

While a broad peak can be observed around $S=0.08-0.10 \AA^{-1}$ for $\left[C_{4} C_{1} i m\right]\left[N T f_{2}\right]$, a reliable peak fit for this feature could not be obtained so it has been excluded from the Figure 3. Nonetheless, it appears that a peak with a correlation distance of approximately $11 \AA \AA$ exists in this IL which is consistent with previous extrapolations for the $\left[C_{n} C_{1} i m\right]\left[N_{T f}\right]$ homologous series. ${ }^{39}$ This should be considered when examining the trends in Figure 3.
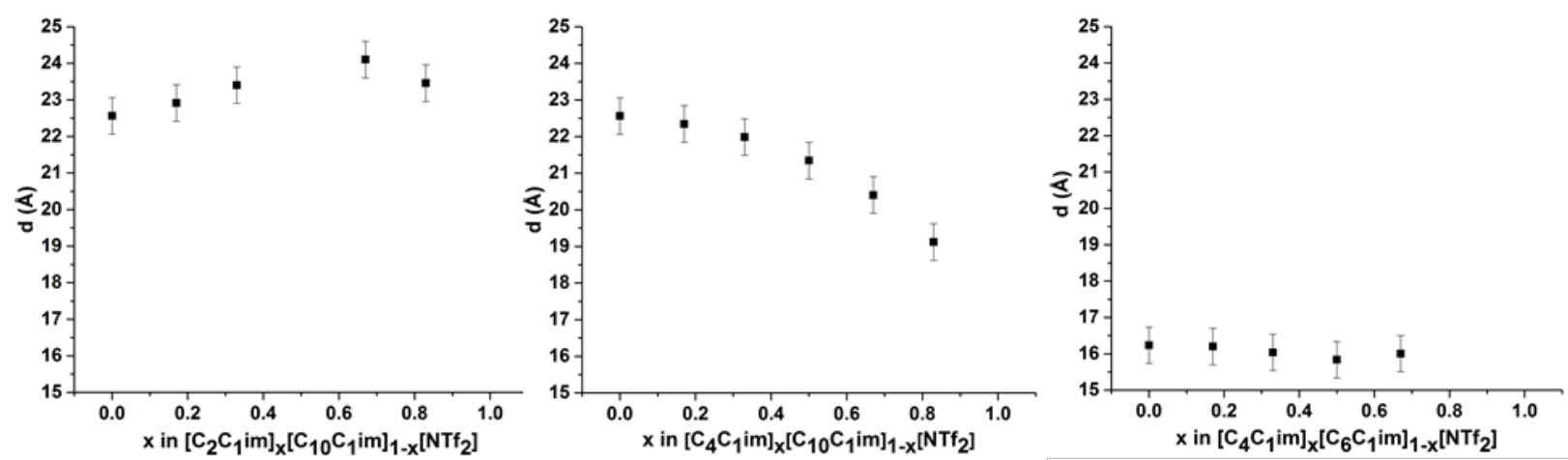

Figure 3. Correlation distances for peak I as a function of $x$ for the (left to right): $\left[C_{2} C_{1} i m\right]_{x}\left[C_{10} C_{1} i m\right]_{1-x}\left[N T f_{2}\right],\left[C_{4} C_{1} i m\right]_{x}\left[C_{10} C_{1} i m\right]_{1-x}\left[N T f_{2}\right]$ and $\left[C_{4} C_{1} i m\right]_{x}\left[C_{6} C_{1} i m\right]_{1-x}\left[N T f_{2}\right]$ mixtures.
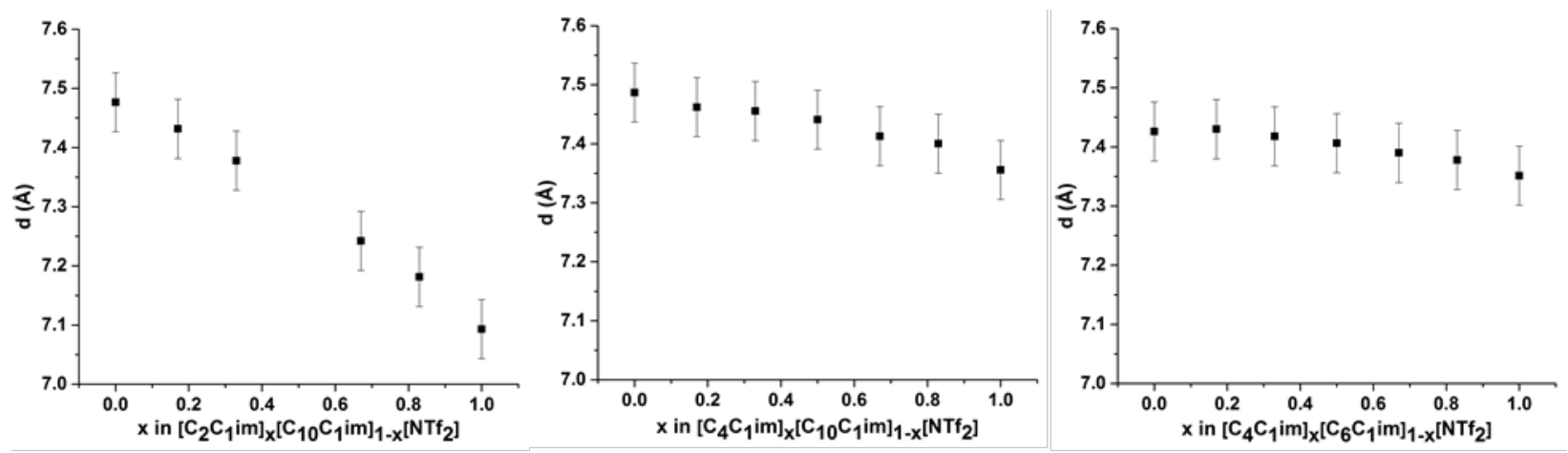

Figure 4. Correlation distances for peak II as a function of $x$ for the (left to right): $\left[C_{2} C_{1} i m\right]_{x}\left[C_{10} C_{1} i m\right]_{1-x}\left[N T f_{2}\right],\left[C_{4} C_{1} i m\right]_{x}\left[C_{10} C_{1} i m\right]_{1-x}\left[N T f_{2}\right]$ and $\left[C_{4} C_{1} i m\right]_{x}\left[C_{6} C_{1} i m\right]_{1-x}\left[N T f_{2}\right]$ mixtures.

For the $\left[\mathrm{C}_{2} \mathrm{C}_{1} \mathrm{im}\right]_{\mathrm{x}}\left[\mathrm{C}_{10} \mathrm{C}_{1} \mathrm{im}\right]_{1-\mathrm{x}}\left[\mathrm{NTf}_{2}\right]$ mixtures, it is evident that the size of the alkyl chain correlation increases slightly with $\left[\mathrm{C}_{2} \mathrm{C}_{1} \mathrm{im}\right]^{+}$ concentration despite this cation not being capable of interacting with the apolar regions. Such an effect has been previously observed for $\left[C_{2} C_{1} i m\right]_{x}\left[C_{12} C_{1} i m\right]_{1-x}\left[N T f_{2}\right]$ mixtures. ${ }^{34}$ This is attributed to the stretching of the polar domains due to the inclusion of the $\left[\mathrm{C}_{2} \mathrm{C}_{1} \mathrm{im}\right]^{+}$cation. The correlation distance of peak II of this mixture shows a linear decrease with increasing proportion of $\left[\mathrm{C}_{2} \mathrm{C}_{1} \mathrm{im}\right]^{+}$cations in the mixture. This is consistent with the inclusion of the smaller ion within the polar domain causing a decrease in interion distances due to reduced steric effects arising from the shorter alkyl chain. Despite the decreased interion distance, this remains consistent with a net stretching effect on the polar domain as the ethyl chains of the $\left[C_{2} C_{1} i m\right]^{+}$cation are unable to interact 
effectively with the apolar domains meaning the entire $\left[\mathrm{C}_{2} \mathrm{C}_{1} \mathrm{im}\right]^{+}$cation is then incorporated within the polar domain. The linearity of the change in peak II correlation distance suggests a random substitution of cations in the polar domains, in line with studies that indicate the strong dissociation of ions within the polar regions of ionic liquids. ${ }^{15,76}$ The persistence of peak I and the domain size until very high proportions of $\left[\mathrm{C}_{2} \mathrm{C}_{1} \mathrm{im}\right]^{+}(\mathrm{x}>0.83)$ indicates that the solvophobic exclusion of alkyl chains from ions is retained in this mixture even as significant cation substitution occurs.

For the $\left[\mathrm{C}_{4} \mathrm{C}_{1} \mathrm{im}\right]_{x}\left[\mathrm{C}_{10} \mathrm{C}_{1} \mathrm{im}\right]_{1-\mathrm{x}}\left[\mathrm{NTf}_{2}\right]$ mixtures, peak I shows that the relative alkyl chain correlation distance decreases with increasing $\left[\mathrm{C}_{4} \mathrm{C}_{1} \mathrm{im}\right]^{+}$concentration, in contrast with the trend observed for the $\left[\mathrm{C}_{2} \mathrm{C}_{1} \mathrm{im}\right]_{x}\left[\mathrm{C}_{10} \mathrm{C}_{1} \mathrm{im}\right]_{1-\mathrm{x}}\left[\mathrm{NTf} \mathrm{f}_{2}\right]$ mixtures. If it is considered that the $x=1$ value is approximately $11 \AA$, this displays a distinctly non-linear decrease with increasing $\left[C_{4} C_{1} i m\right]^{+}$ concentration, where the correlation distance observed is considerably greater than that of a linear interpolation between both simple ILs. Similar non-linear decreases in the polar-apolar correlation distance have been observed for $\left[\mathrm{C}_{6} \mathrm{C}_{1} \mathrm{im}\right]_{x}\left[\mathrm{C}_{10} \mathrm{C}_{1} \mathrm{im}\right]_{1-\mathrm{x}} \mathrm{Cl}$ mixtures although these were not as pronounced as the trend observed here. ${ }^{31}$ This trend can be explained by considering that the butyl chains of $\left[\mathrm{C}_{4} \mathrm{C}_{1} \mathrm{im}\right]^{+}$, unlike the ethyl chains of $\left[\mathrm{C}_{2} \mathrm{C}_{1} \mathrm{im}\right]^{+}$, are able to be incorporated within the apolar domains created by the $\left[\mathrm{C}_{10} \mathrm{C}_{1} \mathrm{im}\right]^{+}$cation. The non-linearity arises from the significantly larger dimension of the decyl chain of the $\left[\mathrm{C}_{10} \mathrm{C}_{1} \text { im }\right]^{+}$cation which enforces a relatively large distance between the polar regions along the alkyl chain axis even when it is present in fairly low proportions. The significantly reduced variation in peak $I$ for the $\left[\mathrm{C}_{4} \mathrm{C}_{1} \mathrm{im}\right]_{x}\left[\mathrm{C}_{10} \mathrm{C}_{1} \mathrm{im}\right]_{1-x}\left[\mathrm{NTf}_{2}\right]$ mixtures compared to $\left[\mathrm{C}_{2} \mathrm{C}_{1} \mathrm{im}\right]_{x}\left[\mathrm{C}_{10} \mathrm{C}_{1} \mathrm{im}\right]_{1-\mathrm{x}}\left[\mathrm{NTf}_{2}\right]$ demonstrates that the disruption to ion packing by the butyl and decyl chains within the polar regions is similar, with the slight variation most likely caused by a small degree of coiling of the longer decyl chain due to dispersive interactions with the $\left[\mathrm{NTf}_{2}\right]^{-}$anion, as has been proposed previously. ${ }^{23,77}$

The $\left[\mathrm{C}_{4} \mathrm{C}_{1} \mathrm{im}\right]_{\mathrm{x}}\left[\mathrm{C}_{6} \mathrm{C}_{1} \mathrm{im}\right]_{1-\mathrm{x}}\left[\mathrm{NTf}_{2}\right]$ mixtures display a constant value for peak I, within experimental error, as the composition is varied. This correlation distance is equivalent to that observed for simple $\left[C_{6} C_{1} i m\right]\left[N T f_{2}\right]$ although larger than that of $\left[C_{4} C_{1} i m\right]\left[N T f_{2}\right]$. As in the $\left[\mathrm{C}_{4} \mathrm{C}_{1} \mathrm{im}\right]_{x}\left[\mathrm{C}_{10} \mathrm{C}_{1} \mathrm{im}\right]_{1-\mathrm{x}}\left[\mathrm{NTf}_{2}\right]$ mixtures above, this suggests that the structure of the apolar domain is dominated by the cation in the mixture that bears the largest alkyl chain. The lack of any evident decrease in the correlation distance of peak I may arise from the broad peaks observed for these mixtures and the relative similarity of the alkyl chain length of the $\left[\mathrm{C}_{4} \mathrm{C}_{1} \mathrm{im}\right]^{+}$and $\left[\mathrm{C}_{6} \mathrm{C}_{1} \mathrm{im}\right]^{+}$ cations meaning a subtle decrease is likely to lie within experimental error. The peak II positions of the simple $\left[\mathrm{C}_{4} \mathrm{C}_{1}\right.$ im] $\left[\mathrm{NTf}_{2}\right]$ and $\left[\mathrm{C}_{6} \mathrm{C}_{1} \mathrm{im}\right]\left[\mathrm{NTf}_{2}\right]$ ILs lie marginally outside of experimental error, with the larger correlation distance for $\left[\mathrm{C}_{6} \mathrm{C}_{1} \mathrm{im}\right]\left[\mathrm{NTf}_{2}\right]$ likely to be due to subtle dispersive interactions between the alkyl chain and the anion as highlighted above. The correlation distances for peak II within the mixtures of these ILs indicate a smooth transition from the $\left[\mathrm{C}_{6} \mathrm{C}_{1}\right.$ im $]\left[N \mathrm{NT}_{2}\right]$ value to that of $\left[\mathrm{C}_{4} \mathrm{C}_{1}\right.$ im $]\left[\mathrm{NTf} \mathrm{f}_{2}\right]$ reiterating the likelihood of random mixing within the polar regions of the ILs.

It is important to stress a general feature shared by the examined mixtures. All of them contain the same common anion, [NTf $]^{-}$ and they differ only in the length of the alkyl chain attached to the imidazolium ring. This ensures that the anion is kept constant in the mixture to eliminate or appreciably reduce any possible interference of the anions on the size of the polar domains. The effect of the anions in the properties of some representative $\left[\mathrm{C}_{4} \mathrm{C}_{1}\right.$ im]-based ionic liquid mixtures has been recently highlighted by Voroshylova et al. ${ }^{78}$ The authors simulated by $\mathrm{MD}$ the behaviour of three possible binary mixtures based on the anions $\left[\mathrm{PF}_{6}\right]^{-}$, $\left[\mathrm{NTf}_{2}\right]^{-}$and tris(pentafluoroethyl)trifluorophosphate ([FAP] $]^{-}$). They have reported that the formation and size of the apolar domains may be influenced by the difference in the anions' size and fluorine content. Both factors caused, in some cases, the reorganization of the apolar domains leading to deviation of the density and excess molar volume from linearity. More specifically related to the present work, we also reported on mixtures containing a common cation $\left(\left[\mathrm{C}_{4} \mathrm{C}_{1} \mathrm{im}\right]^{+}\right)$and different anions such as $\mathrm{Cl}^{-},[\mathrm{SCN}]^{-},[\mathrm{OTf}]^{-}$, $\left[\mathrm{Me}_{2} \mathrm{PO}_{4}\right]^{-}$and $\left[\mathrm{NTf}_{2}\right]^{-23}$. In the paradigmatic case of the mixtures $\left[\mathrm{C}_{4} \mathrm{C}_{1} \mathrm{im}\right] \mathrm{Cl}_{x}\left[\mathrm{NTf}_{2}\right]_{1-x}$, a large decrease of the correlation distance associated with peak I was observed with increasing $x$ (in the 0 to 0.5 range). This effect was not only due to ion size difference, but also to some deep structural rearrangements in the local structure of the liquids connected to the relative basicity of the competing anions. Indeed, replacing a less basic anion with a more basic one induced the displacement of the less basic anion from the $\mathrm{C}(2)-\mathrm{H}$ position of the imidazolium ring to positions above or below the ring. ${ }^{15}$ The alkyl chain, in turn, is known to undergo conformational transitions in order to maximize the dispersive interactions with the less basic anion by assuming a coil-type conformation. ${ }^{77}$ Thus, the electronic properties of the anion influence the size and structure of the apolar domains. This point is of pivotal interest for the present work, where the interpretation of the correlation distances should not be biased by the complex cascade of effects brought about by the different anions.

Hence it can be concluded that the SAXS results indicate that the three mixtures examined display disparate structural behaviour, with the exclusion of ethyl chains of the $\left[C_{2} C_{1} i m\right]^{+}$cation in the $\left[C_{2} C_{1} i m\right]_{x}\left[C_{10} C_{1} i m\right]_{1-x}\left[N T f_{2}\right]$ mixtures and the inclusion of butyl chains within relatively large apolar domains in the $\left.\left[\mathrm{C}_{4} \mathrm{C}_{1} i\right]_{x}\right]_{x}\left[\mathrm{C}_{10} \mathrm{C}_{1} \mathrm{im}\right]_{1-x}\left[\mathrm{NTf}_{2}\right]$ mixtures and within the considerably smaller apolar domains for the $\left[\mathrm{C}_{4} \mathrm{C}_{1} \mathrm{im}\right]_{x}\left[\mathrm{C}_{6} \mathrm{C}_{1} \mathrm{im}\right]_{1-x}\left[\mathrm{NTf}_{2}\right]$ mixtures. Of interest is how this structural behaviour influences the physicochemical properties of these mixtures. To explore this, we have used ${ }^{129}$ Xe NMR as a probe of the free volume within the mixtures, as free volume provides the link between the thermodynamics of mixing and transport properties as we have highlighted previously. ${ }^{23}$

\section{${ }^{129}$ Xe NMR experiments}

The ${ }^{129}$ Xe NMR data for the IL mixtures examined are provided in Figures 5-7, with the tabulated data provided in Tables S4-S6 of the ESI. The plots show both the experimental chemical shift as a function of the mole fraction $(x)$ of the shorter alkyl chain component and the chemical shifts calculated by linear interpolation as $\delta_{\text {calcd }}=x \delta_{1}+(1-x) \delta_{2}$, where $\delta_{1}$ and $\delta_{2}$ are the experimental 
chemical shifts of the simple ILs. The deviations from linearity are quite clear for $\left[C_{2} C_{1} i m\right]_{x}\left[C_{10} C_{1} i m\right]_{1-x}\left[N T f_{2}\right]$, small but not negligible for $\left[\mathrm{C}_{4} \mathrm{C}_{1} \mathrm{im}\right]_{x}\left[\mathrm{C}_{10} \mathrm{C}_{1} \mathrm{im}\right]_{1-\mathrm{x}}\left[\mathrm{NTf} \mathrm{f}_{2}\right]$ and at the limit of the sensitivity of the method for $\left[\mathrm{C}_{4} \mathrm{C}_{1} \mathrm{im}\right]_{\mathrm{x}}\left[\mathrm{C}_{6} \mathrm{C}_{1} \mathrm{im}\right]_{1-\mathrm{x}}\left[\mathrm{NTf} \mathrm{f}_{2}\right]$.

When comparing Xe NMR data in various solvents, it is important that the systems are the same standard state. To enable this, the same reduced temperature $T_{r}=T / T_{c r}$. (T: working temperature, $T_{c r}$ : critical temperature) should be used. Given the high critical temperatures of ILs $(>1000 \mathrm{~K}$ ), the reduced temperatures for all of the ILs examined here are approximately the same, thus the chemical shift data can be safely compared with each other. ${ }^{66}$

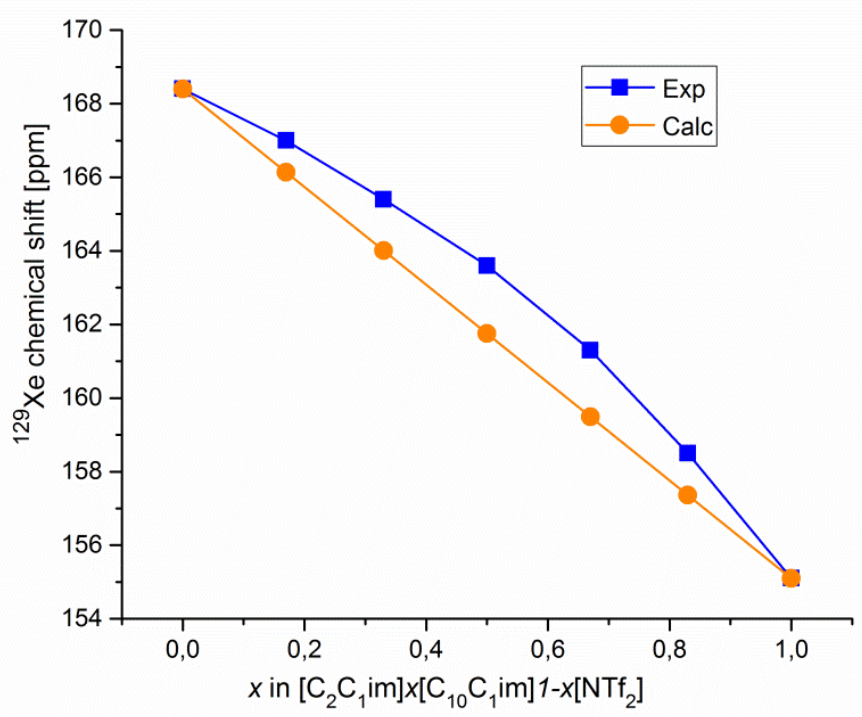

Figure 5. Experimental (squares) and calculated (circles) ${ }^{129}$ Xe chemical shift for for mixture $\left[\mathrm{C}_{2} \mathrm{C}_{1} i \mathrm{im}\right]_{\mathrm{x}}\left[\mathrm{C}_{6} \mathrm{C}_{1} \text { im }\right]_{1-\mathrm{x}}\left[\mathrm{NTf} \mathrm{f}_{2}\right]$. The calculated chemical shift is defined in the text.

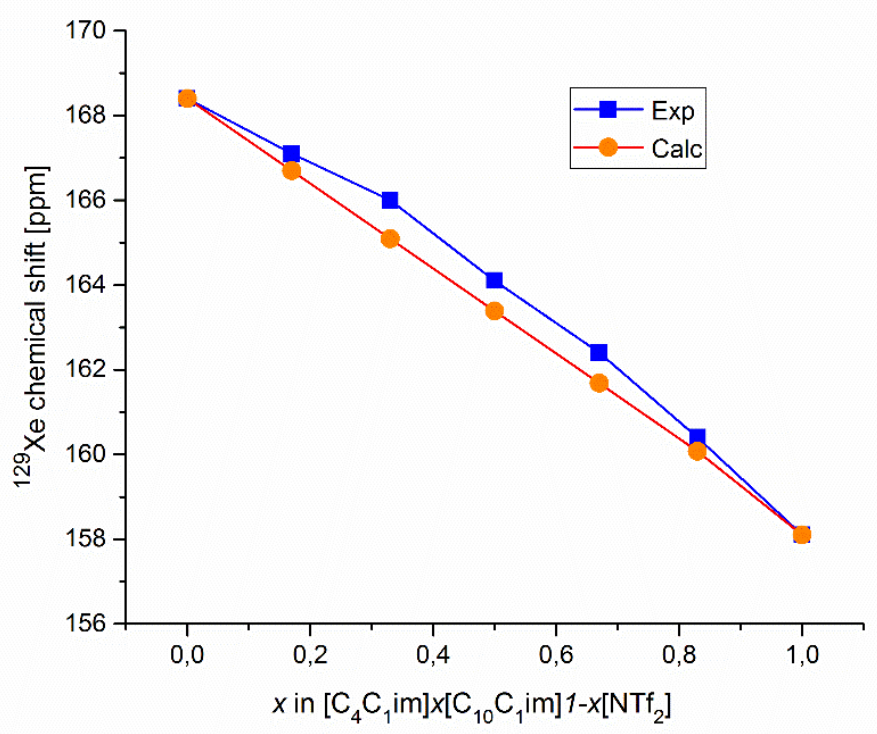

Figure 6. Experimental (squares) and calculated (circles) ${ }^{129}$ Xe chemical shift for mixture $\left[\mathrm{C}_{4} \mathrm{C}_{1} \mathrm{im}\right]_{\times}\left[\mathrm{C}_{10} \mathrm{C}_{1} \mathrm{im}\right]_{1-\mathrm{x}}\left[\mathrm{NTf} \mathrm{f}_{2}\right]$. The calculated chemical shift is defined in the text. 


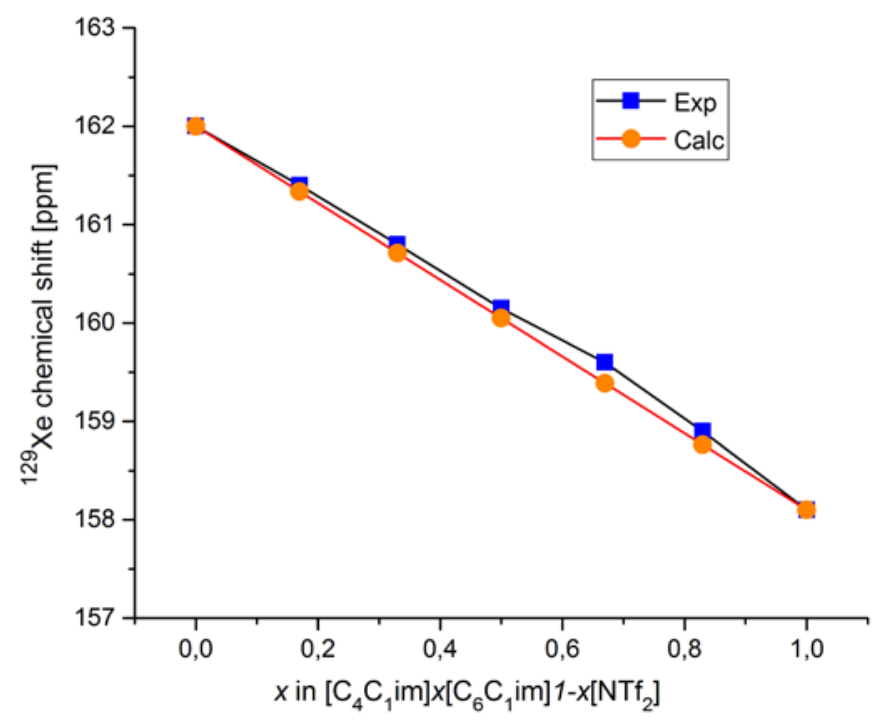

Figure 7. Experimental (squares) and calculated (cirlces) ${ }^{129}$ Xe chemical shift for mixture $\left[\mathrm{C}_{4} \mathrm{C}_{1} i \mathrm{im}\right]_{\times}\left[\mathrm{C}_{6} \mathrm{C}_{1} \mathrm{im}\right]_{1-\mathrm{x}}\left[\mathrm{NTf} \mathrm{f}_{2}\right]$. The calculated chemical shift is defined in the text.

The observed positive deviations mean that the observed Xe chemical shift is larger than expected on the basis of a linear change of chemical shift versus molar fraction. Such deviations can be better highlighted by plotting the excess chemical shift $\delta^{\mathrm{E}}$ as a function of $x$ for the three mixtures considered in this work. $\delta^{\mathrm{E}}$ is defined as $\delta-\left(x \delta_{1}+(1-x) \delta_{2}\right)$, where $\delta$ is the measured chemical shift, $\delta_{1}$ and $\delta_{2}$ are the experimental chemical shifts of the pure components. The results are shown in Figure 8 . The error bars correspond to an estimated uncertainty of $\pm 0.2 \mathrm{ppm}$ for the $\delta^{\mathrm{E}}$ values.

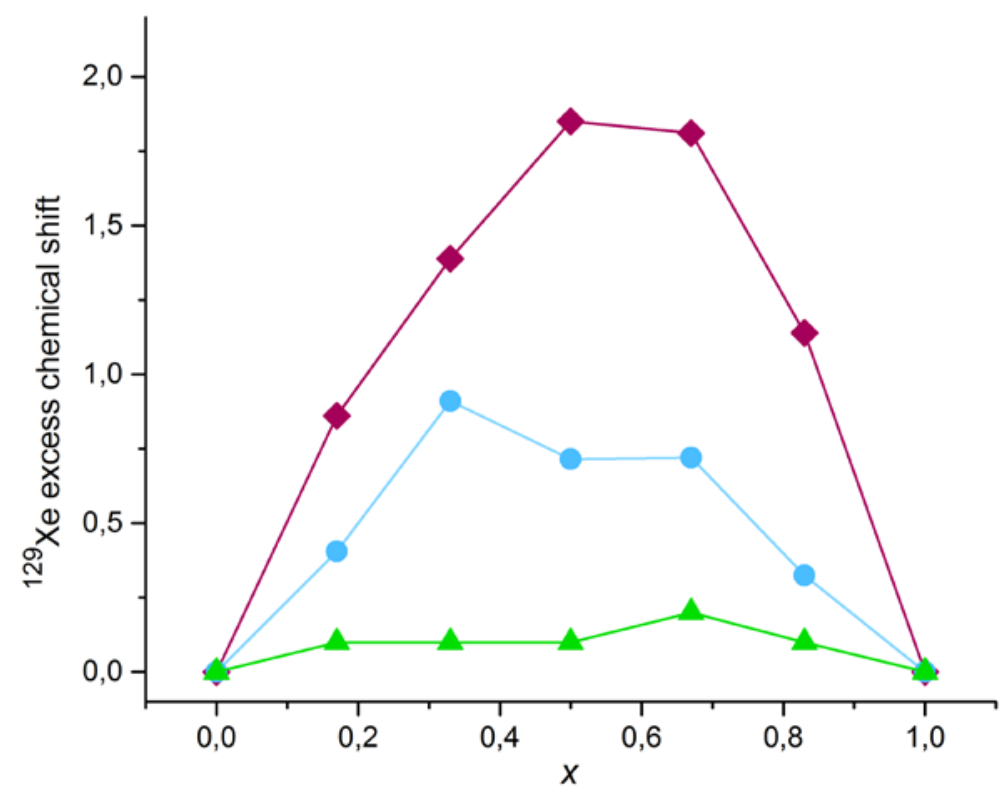

Figure 8. Plot of $\delta^{E}$ vs $x$ in $\left[C_{2} C_{1} i m\right]_{x}\left[C_{10} C_{1} i m\right]_{1-x}\left[N T f_{2}\right]$ (diamonds), $\left[C_{4} C_{1} i m\right]_{x}\left[C_{10} C_{1} i m\right]_{1-x}\left[N T f_{2}\right]$ (circles) and $\left[C_{4} C_{1} i m\right]_{x}\left[C_{6} C_{1} i m\right]_{1-x}\left[N T f_{2}\right]$ (triangles)

Figure 8 shows that the mixing of ILs differing only in their alkyl chain length leads to positive deviations with respect to the linear interpolation. The positive deviations mean that the observed chemical shift is greater than expected and the Xe atoms undergo extra deshielding effects. The intensity of the deviations seems to be linked to the relative length of the alkyl chains on the imidazolium ring: the larger the difference (e.g. C10 vs C2), the larger and better defined the ${ }^{129}$ Xe excess chemical shift. The $\left[\mathrm{C}_{4} \mathrm{C}_{1} \mathrm{im}\right]_{x}\left[\mathrm{C}_{6} \mathrm{C}_{1} \mathrm{im}\right]_{1-\mathrm{x}}\left[\mathrm{NTf}_{2}\right]$ is a limiting case where the chain length on both components is similar and the observed effect on the ${ }^{129} \mathrm{Xe}$ excess chemical shift is negligibly small. 
What is the origin of this effect and how can it be related to the mixing process? To address these issues, we need first to rationalize where the $\mathrm{Xe}$ atoms are locate and what type of environment the ${ }^{129}$ Xe chemical shift is likely to monitor. To this end it is useful to consider some recent MD simulations of a model, long alkyl chain imidazolium IL crystal - $\left[\mathrm{C}_{16} \mathrm{C}_{1} \mathrm{im}\right]\left[\mathrm{NO}_{3}\right]{ }^{79} \mathrm{While}$ none of the components used in the present work has an alkyl chain long enough to generate liquid crystalline phases, $\left[\mathrm{C}_{16} \mathrm{C}_{1} \mathrm{im}\right]\left[\mathrm{NO}_{3}\right]$ can be considered a reasonable reference system to mimic the formation and segregation of the polar and apolar domains in our mixtures. The MD simulations pointed out the formation of layers made of the polar parts (imidazolium cations and the anions) separated by a large region of the interdigitated alkyl chains. The segregation of the ions in the polar domain allowed for a close packing of the ions, thus giving rise to stronger cation-anion interactions than in short chained imidazolium based ILs. The MD trajectories clearly showed the formation of density fluctuations in the middle of the hydrophobic domain, generating voids. The voids are thus located in the apolar, liquid like domain. The same author also demonstrated that such voids in the hydrophobic layers are sufficiently large to host Xe atoms. ${ }^{69}$ This is consistent with the data reported by Morgado et al. showing that the ${ }^{129} \mathrm{Xe}$ chemical shifts of Xe dissolved in the homologous series of $\left[C_{n} C_{1} i m\right]\left[N^{2} f_{2}\right]$ salts increase with increasing number of $C$ atoms of the chain, moving asymptotically towards the value of the longest alkane in the same thermodynamic state. ${ }^{66}$ Critically, this suggests that a positive value of $\delta^{\mathrm{E}}$ may arise either from increased wall effects due to the presence of smaller voids, from Eq. 1, and/or the preferential incorporation of Xe within the apolar domain of the IL which results in a downfield shift due to van der Waals interactions between the alkyl chain and Xe atom.

To establish whether the $\delta^{\mathrm{E}}$ observed was related to the excess molar volume $\left(\mathrm{V}^{\mathrm{E}}\right)$, their relationship was examined and is depicted in Figure 9. $V^{E}$ for each mixture was determined from the molar volume which in turn was obtained by triplicate measurements of the density of each IL or IL mixture. We have previously established for mixtures of ILs bearing different anions that changes in $\delta^{E}$ arising primarily from an increase in the size of voids within the liquid structure leads to a negative correlation between $V^{E}$ and $\delta^{E} .23$ This was attributed to the reduced significance of wall effects when larger voids are present. From Figure 9 it is evident that a good correlation between $V^{\mathrm{E}}$ and $\delta^{\mathrm{E}}$ is observed but the slope has the opposite sign to those that have been obtained for IL mixtures previously. The strong positive correlation observed between $V^{E}$ and $\delta^{E}$ suggests that the free volume formed in this case is related to the existence of voids within the apolar domain which possesses an inherently more downfield (larger) chemical shift than voids within the polar regions of the IL. Alternatively, this may be attributed to the proliferation of a greater number of smaller voids within the mixture.

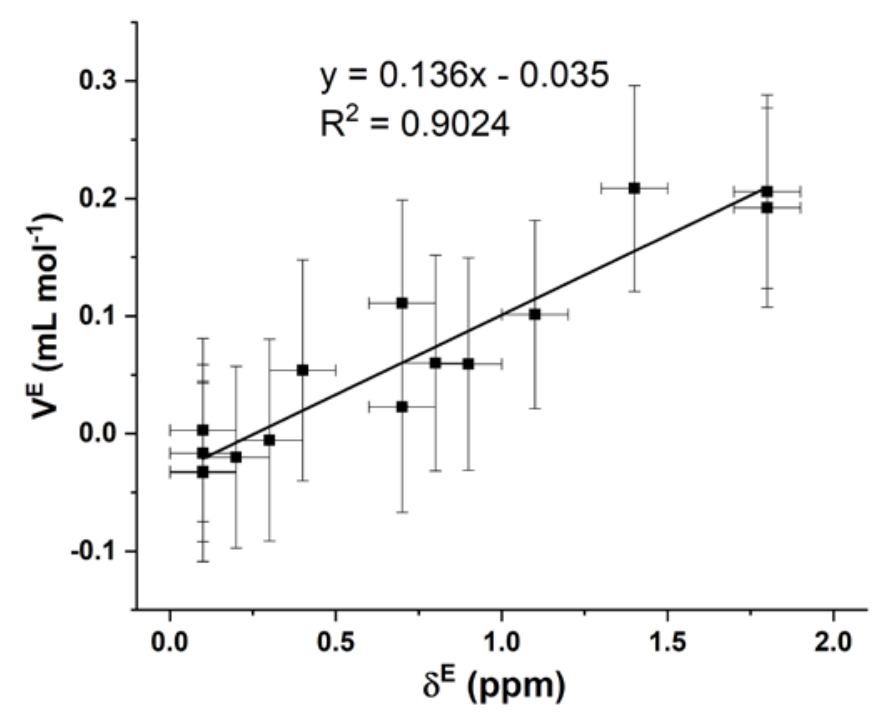

Figure 9. Plot of $\mathrm{V}^{\mathrm{E}}$ versus $\delta^{\mathrm{E}}$ combining data from all of the IL mixtures examined.

In order to gain insight into the mechanisms underlying this relationship, the origin of $\delta$ itself must be examined. For homologous series of molecular liquids, $\delta$ typically increases monotonically but non-linearly with the length of the alkyl chain. Adjustment of $\delta$ by subtracting the volumetric magnetic susceptibility and dividing by the molar density of the solvent has been found to transform this non-linear relationship into a linear one where the characteristic group contribution value of each $-\mathrm{CH}_{2}$ - unit can be determined. ${ }^{80,81}$ To the best of the authors' knowledge, the magnetic susceptibility of ILs has not been determined which precludes the incorporation of these values in the analysis of these data. However, for the $\left[C_{n} C_{1} i m\right]\left[N T f_{2}\right]$ series, a linear relationship between $\delta$ and the length of the longest carbon chain has been observed without the need for the adjustment of the chemical shift values. ${ }^{66}$ The chemical shift divided by the molar density, $\frac{\delta}{\rho}$, is also considerably larger than for molecular liquids owing to the large molecular weights and hence correspondingly small molar density of these ILs so the impact of the magnetic susceptibility on the chemical shift values observed is likely to be small.

To explore trends in the absolute ${ }^{129} \mathrm{Xe}$ NMR chemical shift with increasing alkyl chain length, we have examined the relationship between $\delta$ and $\mathrm{n}_{\mathrm{CH} 2}$ which is the average number of $\mathrm{CH}_{2}$ units per imidazolium cation. This definition avoids any ambiguity about 
the inclusion of carbon atoms on the imidazolium ring or the terminal $\mathrm{CH}_{3}$ units on each alkyl chain. For IL mixtures, we use a weighted average of $\mathrm{CH}_{2}$ groups to determine $\mathrm{n}_{\mathrm{CH} 2}$, for example, in the $\left[\mathrm{C}_{2} \mathrm{C}_{1} \mathrm{im}\right]_{0.50}\left[\mathrm{C}_{10} \mathrm{C}_{1} \mathrm{im}\right]_{0.50}\left[\mathrm{NTf}_{2}\right]$ mixture $\mathrm{n}_{\mathrm{CH} 2}=5.0$. Figure 10 depicts the relationship between $\delta$ and $\mathrm{n}_{\mathrm{CH} 2}$ for these ILs and IL mixtures and Figure 11 the corresponding relationship for $\frac{\delta}{\rho}$. In both cases, the fitted lines were obtained using only the values for the simple ILs to allow any deviation from this trend for the IL mixtures to be clearly observed.

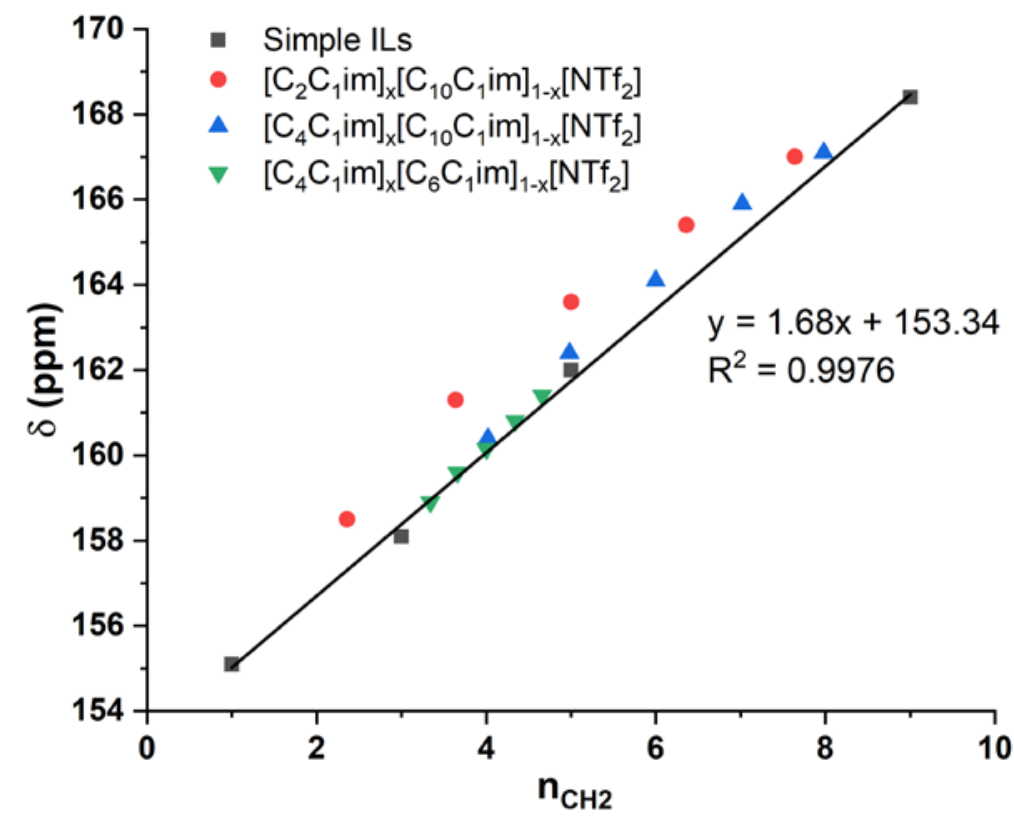

Figure 10. Variation of $\delta$ from ${ }^{129}$ Xe NMR with $\mathrm{n}_{\mathrm{CH} 2}$ for the ILs and IL mixtures examined. Fitted line corresponds only to $\delta$ of the 4 simple ILs.

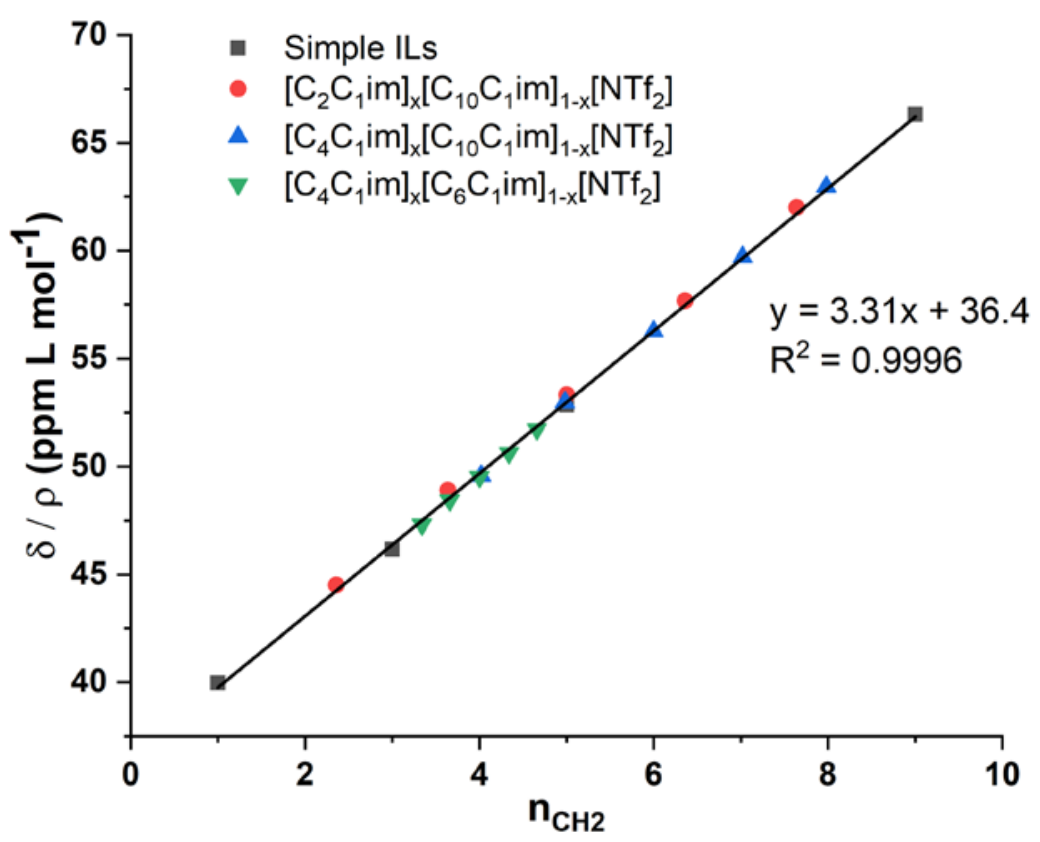

Figure 11. Variation of $\frac{\delta}{\rho}$ from ${ }^{129}$ Xe NMR with $\mathrm{n}_{\mathrm{CH} 2}$ for the ILs and IL mixtures examined. Fitted line corresponds only to $\frac{\delta}{\rho}$ of the 4 simple ILs.

From Figure 10 and 11, some key trends emerge. As has been reported previously, $\delta$ for the simple $\left[\mathrm{C}_{n} \mathrm{C}_{1} \mathrm{im}^{\mathrm{m}}\right]\left[\mathrm{NTf}_{2}\right]$ is linearly related to the length of the alkyl chain. ${ }^{66}$ The deviation from linearity for the IL mixtures increases in line with increasing difference in the alkyl chain length of the mixtures, as has been discussed previously. Critically, this deviation disappears entirely when $\delta$ is normalised to the molar density. In other words, $\delta^{E}$ can be completely explained by considering differences in the molar density of the IL mixtures when compared to a simple IL containing an identical average alkyl chain length. This in turn explains the correlation observed between $\delta^{\mathrm{E}}$ and $\mathrm{V}^{\mathrm{E}}$ as the molar density is the inverse of the molar volume. 
The slope of the line implies a group contribution of $3.31 \pm 0.04 \mathrm{ppm} \mathrm{L} \mathrm{mol}{ }^{-1}$ per $\mathrm{CH}_{2}$ group which is within experimental error of the values of 3.29, 3.30 and 3.28 which have been determined for linear alkanes, alkanols and alkanoic acids respectively. ${ }^{80,82}$ This reinforces that the differences in $\delta$ for these ILs and IL mixtures arise from the solvation of Xe by the alkyl chain. The intercept predicts $\frac{\delta}{\rho}=36.4 \mathrm{ppm} \mathrm{L} \mathrm{mol}{ }^{-1}$ for the $\left[\mathrm{C}_{1} \mathrm{C}_{1} \mathrm{im}\right]\left[\mathrm{NTf}_{2}\right] \mathrm{IL}$ although there is no experimental data currently available to verify this prediction.

Collectively these results illustrate two key points with regard to free volume in these IL mixtures. Firstly, ${ }^{129}$ Xe NMR is an accurate reporter of the excess molar volume of the ILs as is evident by comparison of Figure 10 with Figure 11. Secondly, the excess molar volume generated within these IL mixtures occurs as a result of free volume within the apolar region of the IL as the chemical shift changes observed are consistent with the increasing ability of Xe to sample the void cavities of the alkyl chain domain, experiencing deshielding effects due to $\mathrm{CH}_{2}-\mathrm{Xe}$ and $\mathrm{CH}_{3}-\mathrm{Xe}$ van der Waals interactions. ${ }^{82}$

\section{Thermodynamic interpretation of the results}

It is important to consider the ${ }^{129}$ Xe NMR results in light of the disparate structural behaviour observed from the SAXS experiments. To examine this in a more quantitative manner, we have modelled Xe solvation as an equilibrium process between solvation by each of the components of the IL mixture. By using the actual mole fraction of each IL and the apparent mole fraction of Xe solvated by each IL derived from the value of $\delta$ observed, an equilibrium constant, $\mathrm{K}$, can be evaluated for Xe solvation by each of the IL mixtures. This is depicted by Eq. 2 and 3 where $\mathrm{Xe}_{[\mathrm{CnC1im}][\mathrm{NTf2]}}$ is Xe solvated by the IL $\left[\mathrm{C}_{n} \mathrm{C}_{1} \mathrm{im}_{\mathrm{m}}\left[\mathrm{NTf}_{2}\right]\right.$ and $\mathrm{X}_{\mathrm{Xe}}[\mathrm{CnC1im]}[\mathrm{NTf2]}$ is the mole fraction of $\mathrm{Xe}_{[\mathrm{CnC1im]}[\mathrm{NTf2]}}$ in the solution with further details provided in the ESI. Note that the mole fractions calculated in this way are not the precise mole fraction within the mixture as the absolute mole fraction of solvated Xe in the IL needs to be known to calculate these. Nonetheless, this does not affect the calculated value of K. For the application of this model $m>n$, in other words a value of $K>1$ represents greater interaction with the longer alkyl chain length component of the mixture. The values of $K$ varied randomly with the composition within each mixture so these were averaged for each IL mixture to provide a measure of any increased interaction of Xe with the apolar regions of each IL mixture compared to a weighted average of the simple ILs. This was developed to allow the extent of free volume formation within the apolar domains to be compared amongst each of the mixtures, given the established relationship between Xe solvation and the free volume in these mixtures. The parameters calculated from this model are given in Table 1.

$$
\begin{aligned}
& \mathrm{Xe}_{[\mathrm{CnC1im}][\mathrm{NTf2]}}+\left[\mathrm{C}_{\mathrm{m}} \mathrm{C}_{1} \mathrm{im}\right]\left[\mathrm{NTf}_{2}\right] \rightleftharpoons \mathrm{Xe}_{[\mathrm{CmC1im}][\mathrm{NTf2}]}+\left[\mathrm{C}_{\mathrm{n}} \mathrm{C}_{1} \mathrm{im}\right]\left[\mathrm{NTf}_{2}\right] \\
& K=\frac{x_{[\mathrm{CnC1im}][N T f 2]} x_{X e[\text { CmC1im }][N T f 2]}}{x_{[\mathrm{CmC1im}][N T f 2]} x_{X e[\mathrm{CnC1im}][N T f 2]}}
\end{aligned}
$$

Table 1. Apparent values of $K$ and $\Delta G^{\circ}$ obtained from a preferential solvation model of Xe with the two components of the IL

\begin{tabular}{|c|c|c|}
\hline IL mixture & $\mathbf{K}$ & $\Delta \mathrm{G}^{\circ}\left(\mathrm{kJ} \mathrm{mol}^{-1}\right)$ \\
\hline$\left[\mathrm{C}_{2} \mathrm{C}_{1} \mathrm{im}\right]_{\mathrm{x}}\left[\mathrm{C}_{10} \mathrm{C}_{1} \mathrm{im}\right]_{1-\mathrm{x}}\left[\mathrm{NTf}_{2}\right]$ & $1.73 \pm 0.04$ & $-1.36 \pm 0.06$ \\
\hline$\left[\mathrm{C}_{4} \mathrm{C}_{1} \mathrm{im}\right]_{x}\left[\mathrm{C}_{10} \mathrm{C}_{1} \mathrm{im}\right]_{1-\mathrm{x}}\left[\mathrm{NTf}_{2}\right]$ & $1.44 \pm 0.06$ & $-0.91 \pm 0.10$ \\
\hline$\left[\mathrm{C}_{4} \mathrm{C}_{1} \mathrm{im}\right]_{\times}\left[\mathrm{C}_{6} \mathrm{C}_{1} \mathrm{im}\right]_{1-\mathrm{x}}\left[\mathrm{NTf} \mathrm{f}_{2}\right]$ & $1.17 \pm 0.08$ & $-0.40 \pm 0.17$ \\
\hline
\end{tabular}
mixture. Errors of $K$ are the standard deviations of averaged values, $\Delta G^{\circ}$ errors are propagated from these values.

As would be expected, the values of $K$ are larger than 1 in all cases. This is consistent with the greater propensity of Xe to interact with the apolar domain of the IL as has been discussed. To ascertain whether this effect changes consistently with the difference in alkyl chain length of the mixture, $\Delta \mathrm{G}^{\circ}$ has been plotted against the difference in alkyl chain length for each of the IL mixtures studied and is depicted in Figure 12. 


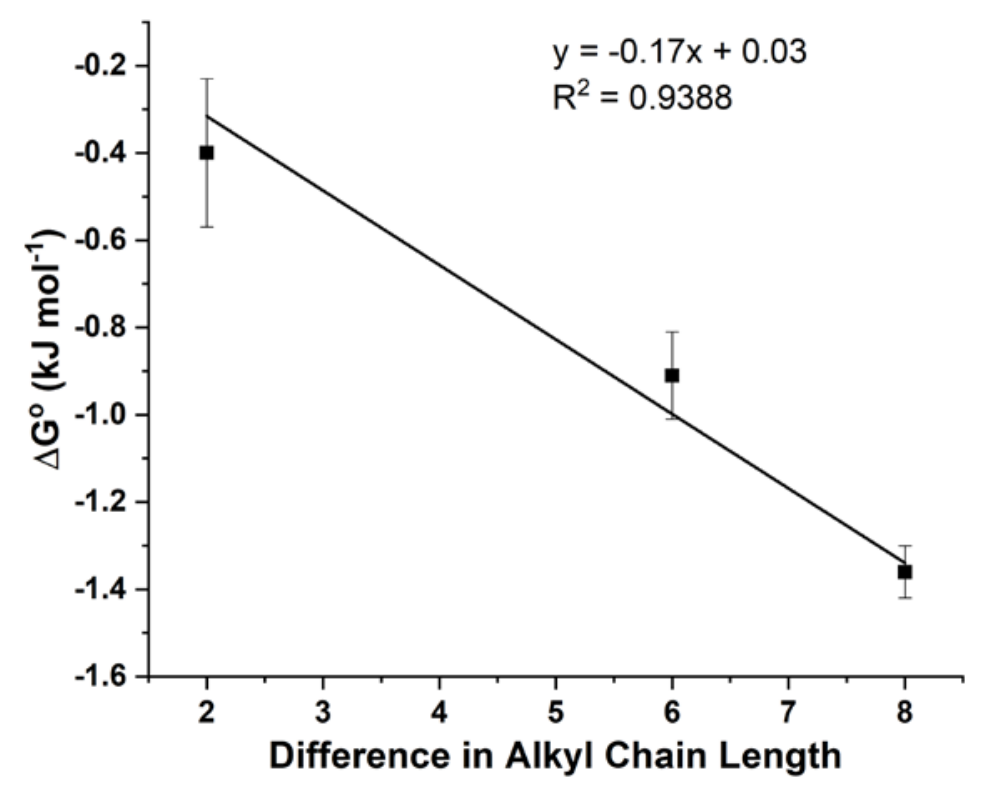

Figure 12. Relationship between $\Delta G^{\circ}$ and the difference in alkyl chain length for the preferential solvation model applied to Xe for the 3 IL mixtures examined.

The results depicted in Figure 12 are physically intuitive. The intercept lies within experimental error of $0(0.03 \pm 0.20)$ indicating that there is no preferred interaction of Xe when both IL cations are the same. The preference for Xe to interact with the longer alkyl chain IL increases with increasing difference in the alkyl chain length between the two ILs. In other words, the greater the contribution to the apolar domain by a single IL, the stronger the preference for Xe to interact with that IL. This is also consistent with the previous discussion of Xe solvation in the apolar regions of the IL and the formation of free volume within this space. Finally, the small size of the preferences is consistent with the small magnitude of $\mathrm{V}^{\mathrm{E}}$ for each of the IL mixtures relative to the molar volumes of the ILs.

The most notable outcome from Figure 12 is that the preference changes linearly with the difference in alkyl chain length for the IL mixtures studied. While it could be argued that the data point corresponding to the $\left[\mathrm{C}_{2} \mathrm{C}_{1} \mathrm{im}\right]_{\mathrm{x}}\left[\mathrm{C}_{10} \mathrm{C}_{1} \mathrm{im}\right]_{1-\mathrm{x}}\left[\mathrm{NTf}_{2}\right]$ may lie marginally below that which would be expected from the other two mixtures, such an effect is subtle $\left(<0.2 \mathrm{~kJ} \mathrm{~mol}^{-1}\right)$ relative to the significant differences in structural behaviour affecting the apolar domain observed across these 3 mixtures. This outcome implies that changes in excess free volume induced by mixing ILs that only differ in the length of the alkyl chain on the ions are predominantly determined by the size of the alkyl chain mismatch and not the specific details of the structural rearrangements that result, at least for the $\left[C_{n} C_{1} i m\right]\left[N T f_{2}\right]$ homologous series. The magnitude of all of these effects remains small, consistent with numerous other studies of ILs that suggest that ILs tend to form close to ideal mixtures in the majority of cases. ${ }^{12,14,23,28,57,83}$

On a molecular level, this can be conceptualised by considering the aggregation effects underpinning the formation of the apolar domain. When one alkyl chain is substantially larger than the other in the mixture, the dimensions of the apolar domain will be largely determined by this alkyl chain, regardless of whether the shorter alkyl chain can be incorporated in the apolar domain. As the proportion of the shorter alkyl chain in the mixture increases, its markedly smaller size reduces the ability of the longer alkyl chain to form a continuous apolar domain. This mismatch and the structural discontinuities that result increase the free volume within the apolar domain, albeit only to a small extent, regardless of whether there is an interaction with the shorter chain in the apolar domain or not. From the Xe NMR results it appears likely that this free volume arises in the form of an increased quantity rather than size of voids within the liquid structure, that is, the discontinuities in the apolar domain caused by alkyl chain mismatch lead to an increased number of small void spaces within the liquid structure, in turn leading to an increased ability of Xe to experience van der Waals interactions with the alkyl chains causing deshielding.

\section{Conclusions}

A combined SAXS and ${ }^{129}$ Xe NMR investigation of three IL mixtures: $\left[C_{2} C_{1} i m\right]_{x}\left[C_{10} C_{1} i m\right]_{1-x}\left[N T f_{2}\right],\left[C_{4} C_{1} i m\right]_{x}\left[C_{10} C_{1} i m\right]_{1-x}\left[N T f_{2}\right]$ and $\left[C_{4} C_{1} i m\right]_{x}\left[C_{6} C_{1} i m\right]_{1-x}\left[N T f_{2}\right]$ was performed. The primary structural difference between these mixtures that was determined by $S A X S$ related to the inclusion of the shorter alkyl chain within the apolar domains. For the $\left[\mathrm{C}_{2} \mathrm{C}_{1} \mathrm{im}\right]_{x}\left[\mathrm{C}_{10} \mathrm{C}_{1} \mathrm{im}\right]_{1-\mathrm{x}}\left[\mathrm{NTf}_{2}\right]$ mixtures the addition of $\left[\mathrm{C}_{2} \mathrm{C}_{1}\right.$ im] $\left[\mathrm{NTf}_{2}\right]$ led to a more tightly held, swollen polar domain with the ethyl chains of the $\left[\mathrm{C}_{2} \mathrm{C}_{1} \text { im }\right]^{+}$cation excluded from the apolar domain as shown by the increasing size of these domains with increasing $\left[C_{2} C_{1} i m\right]^{+}$concentration. In contrast, the size of the apolar domains of the $\left[\mathrm{C}_{4} \mathrm{C}_{1} \mathrm{im}\right]_{x}\left[\mathrm{C}_{10} \mathrm{C}_{1} \mathrm{im}\right]_{1-\mathrm{x}}\left[\mathrm{NTf}_{2}\right]$ mixtures decreased with increasing $\left[\mathrm{C}_{4} \mathrm{C}_{1} \text { im }\right]^{+}$content due to the interaction between the butyl and decyl chains. In all cases the size of the apolar domains was dominated by the dimensions of the largest alkyl chain in the mixture. 
From the ${ }^{129}$ Xe NMR results it was found that the Xe atom was an excellent probe of the excess molar volume within these IL mixtures. The observed change in chemical shift indicated that the increase in free volume observed arises within the apolar region of the IL and is likely to consist of an increased number of smaller voids within the liquid structure. Modelling the deviations in the Xe NMR chemical shift indicated that the free volume effects observed can be quantitatively accounted for solely by the difference in alkyl chain length of ILs in the IL mixture, regardless of whether the IL alkyl chains were solvated in the apolar domains or not.

Collectively, these results explicitly identify the structural origin of excess free volume within IL mixtures containing different alkyl chain lengths and demonstrate that the magnitude of this excess free volume can be predicted in a straightforward way from the chemical structure of the ions. As the excess free volume for mixtures containing different length alkyl chains arises from the apolar regions and our previous findings suggest that Coulombic interactions with the polar domains govern excess free volume when different types of ions are mixed, ${ }^{23}$ there is a significant likelihood that such processes operate additively and independently of each other. We are currently actively exploring these effects. Given shorter alkyl chain ILs often have lower viscosity and improved conductivity relative to their longer alkyl chain derivatives, this insight into these mixtures provides a pathway for the design of nanostructured ILs that possess more favourable physicochemical properties.

\section{Acknowledgements}

We acknowledge Diamond Light Source for the provision of synchrotron beamtime and we would like to thank Dr. Olga Shebanov for assistance using beamline 122. The authors acknowledge an ERC Advanced Investigator Grant held by TW for funding. CCW is supported by a Marsden Fund Fast Start grant.

\section{References}

1. J. P. Hallett and T. Welton, Chem. Rev., 2011, 111, 3508-3576.

2. C. C. Weber, A. F. Masters and T. Maschmeyer, Green Chem., 2013, 15, 2655-2679.

3. Z. Ma, J. Yu and S. Dai, Adv. Mater., 2010, 22, 261-285.

4. M. Armand, F. Endres, D. R. MacFarlane, H. Ohno and B. Scrosati, Nat. Mater., 2009, 8, 621-629.

5. T. Welton, Chem. Rev., 1999, 99, 2071-2083.

6. J. B. Harper and M. N. Kobrak, Mini-Rev. Org. Chem., 2006, 3, 253-269.

7. A. Brandt, J. Gräsvik, J. P. Hallett and T. Welton, Green Chem., 2013, 15, 550-583.

8. X. Han and D. W. Armstrong, Acc. Chem. Res., 2007, 40, 1079-1086.

9. C. M. Graham and J. L. Anderson, in lonic Liquids UnCOILed, eds. N. V. Plechkova and K. R. Seddon, John Wiley \& Sons, Inc., Hoboken, NJ, USA, 2013, ch. 9, pp. 87-118.

10. D. R. MacFarlane, N. Tachikawa, M. Forsyth, J. M. Pringle, P. C. Howlett, G. D. Elliot, J. H. Davis, Jr., M. Watanabe, P. Simon and C. A. Angell, Energy Environ. Sci., 2014, 7, 232-250.

11. M. Watanabe, M. L. Thomas, S. Zhang, K. Ueno, T. Yasuda and K. Dokko, Chem. Rev., 2017, 117, 7190-7239.

12. H. Niedermeyer, J. P. Hallett, I. J. Villar-Garcia, P. A. Hunt and T. Welton, Chem. Soc. Rev., 2012, 41, 7780-7802.

13. M. Freemantle, Chem. Eng. News, 1998, 76, 32-37.

14. M. T. Clough, C. R. Crick, J. Gräsvik, P. A. Hunt, H. Niedermeyer, T. Welton and O. P. Whitaker, Chem. Sci., 2015, 6, 1101-1114.

15. R. P. Matthews, I. J. Villar-Garcia, C. C. Weber, J. Griffith, F. Cameron, J. P. Hallett, P. A. Hunt and T. Welton, Phys. Chem. Chem. Phys., 2016, 18, 8608-8624.

16. H. F. D. Almeida, J. N. Canongia Lopes, L. P. N. Rebelo, J. A. P. Coutinho, M. G. Freire and I. M. Marrucho, J. Chem. Eng. Data, 2016, 61, 2828-2843.

17. L. F. Lepre, J. Szala-Bilnik, A. A. H. Padua, M. Traikia, R. A. Ando and M. F. Costa Gomes, Phys. Chem. Chem. Phys., 2016, 18, 23285-23295.

18. Y. O. Andriyko, W. Reischl and G. E. Nauer, Journal of Chemical \& Engineering Data, 2009, 54, 855860.

19. M. Montanino, M. Moreno, F. Alessandrini, G. B. Appetecchi, S. Passerini, Q. Zhou and W. A. Henderson, Electrochim. Acta, 2012, 60, 163-169.

20. M. Larriba, S. García, P. Navarro, J. García and F. Rodríguez, J. Chem. Eng. Data, 2012, 57, 13181325.

21. H. Ning, M. Hou, Q. Mei, Y. Liu, D. Yang and B. Han, Sci. China Chem., 2012, 55, 1509-1518.

22. G. Annat, M. Forsyth and D. R. MacFarlane, J. Phys. Chem. B, 2012, 116, 8251-8258. 
23. N. J. Brooks, F. Castiglione, C. Doherty, A. Dolan, A. J. Hill, P. A. Hunt, R. P. Matthews, M. Mauri, A. Mele, R. Simonutti, I. J. Villar-Garcia, C. C. Weber and T. Welton, Chem. Sci., 2017, 8, 6359-6374.

24. M. Kanakubo, T. Makino and T. Umecky, J. Mol. Liq., 2016, 217, 112-119.

25. A. Podgoršek, J. Jacquemin, A. A. H. Pádua and M. F. Costa Gomes, Chem. Rev., 2016.

26. J. J. Fillion and J. F. Brennecke, J. Chem. Eng. Data, 2017, 62, 1884-1901.

27. A. Arce, M. J. Earle, S. P. Katdare, H. Rodríguez and K. R. Seddon, Chem. Commun., 2006, 25482550.

28. J. N. Canongia Lopes, T. C. Cordeiro, J. M. S. S. Esperança, H. J. R. Guedes, S. Huq, L. P. N. Rebelo and K. R. Seddon, J. Phys. Chem. B, 2005, 109, 3519-3525.

29. T. Pott and P. Méléard, Phys. Chem. Chem. Phys., 2009, 11, 5469-5475.

30. O. Hollóczki, M. Macchiagodena, H. Weber, M. Thomas, M. Brehm, A. Stark, O. Russina, A. Triolo and B. Kirchner, ChemPhysChem, 2015, 16, 3325-3333.

31. O. Russina and A. Triolo, Faraday Discuss., 2012, 154, 97-109.

32. T. L. Greaves, D. F. Kennedy, N. Kirby and C. J. Drummond, Phys. Chem. Chem. Phys., 2011, 13, 13501-13509.

33. O. Russina, F. Lo Celso, N. V. Plechkova and A. Triolo, J. Phys. Chem. Lett., 2017, 8, 1197-1204.

34. D. W. Bruce, C. P. Cabry, J. N. C. Lopes, M. L. Costen, L. D’Andrea, I. Grillo, B. C. Marshall, K. G. McKendrick, T. K. Minton, S. M. Purcell, S. Rogers, J. M. Slattery, K. Shimizu, E. Smoll and M. A. Tesa-Serrate, J. Phys. Chem. B, 2017, 121, 6002-6020.

35. C. P. Cabry, L. D’Andrea, K. Shimizu, I. Grillo, P. Li, S. Rogers, D. W. Bruce, J. N. Canongia Lopes and J. M. Slattery, Faraday Discuss., 2018, 206, 265-289.

36. Y. Wang and G. A. Voth, J. Am. Chem. Soc., 2005, 127, 12192-12193.

37. J. N. A. Canongia Lopes and A. A. H. Padua, J. Phys. Chem. B, 2006, 110, 3330-3335.

38. A. Triolo, O. Russina, H.-J. Bleif and E. Di Cola, J. Phys. Chem. B, 2007, 111, 4641-4644.

39. O. Russina, A. Triolo, L. Gontrani, R. Caminiti, D. Xiao, L. G. Hines, R. A. Bartsch, E. L. Quitevis, N. Plechkova and K. R. Seddon, J. Phys.: Condens. Matter, 2009, 21, 424121.

40. K. Shimizu, C. E. S. Bernardes and J. N. Canongia Lopes, J. Phys. Chem. B, 2014, 118, 567-576.

41. C. C. Weber, A. F. Masters and T. Maschmeyer, Angew. Chem. Int. Ed., 2012, 51, 11483-11486.

42. C. C. Weber, A. F. Masters and T. Maschmeyer, Org. Biomol. Chem., 2013, 11, 2534-2542.

43. D. W. Bruce, Y. Gao, J. N. Canongia Lopes, K. Shimizu and J. M. Slattery, Chem. Eur. J., 2016, 22, 16113-16123.

44. H. J. Jiang, R. Atkin and G. G. Warr, Curr. Opin. Green Sust. Chem., 2018, 12, 27-32.

45. R. Hayes, G. G. Warr and R. Atkin, Chem. Rev., 2015, 115, 6357-6426.

46. M. Yang, P. S. Campbell, C. C. Santini and A.-V. Mudring, Nanoscale, 2014, 6, 3367-3375.

47. T. Gutel, J. Garcia-Anton, K. Pelzer, K. Philippot, C. C. Santini, Y. Chauvin, B. Chaudret and J.-M. Basset, J. Mater. Chem., 2007, 17, 3290-3292.

48. T. Gutel, C. C. Santini, K. Philippot, A. Padua, K. Pelzer, B. Chaudret, Y. Chauvin and J.-M. Basset, J. Mater. Chem., 2009, 19, 3624-3631.

49. I. M. Gindri, C. P. Frizzo, C. R. Bender, A. Z. Tier, M. A. P. Martins, M. A. Villetti, G. Machado, L. C. Rodriguez and D. C. Rodrigues, ACS Appl. Mater. Interfaces, 2014, 6, 11536-11543.

50. O. Russina, A. Triolo, L. Gontrani and R. Caminiti, J. Phys. Chem. Lett., 2012, 3, 27-33.

51. J. J. Hettige, H. K. Kashyap, H. V. R. Annapureddy and C. J. Margulis, J. Phys. Chem. Lett., 2013, 4, 105-110.

52. H. V. R. Annapureddy, H. K. Kashyap, P. M. De Biase and C. J. Margulis, J. Phys. Chem. B, 2010, 114, 16838-16846.

53. T. Méndez-Morales, J. Carrete, J. R. Rodríguez, Ó. Cabeza, L. J. Gallego, O. Russina and L. M. Varela, Phys. Chem. Chem. Phys., 2015, 17, 5298-5307.

54. K. Shimizu, M. F. Costa Gomes, A. A. H. Padua, L. P. N. Rebelo and J. N. Canongia Lopes, J. Mol. Struc:THEOCHEM, 2010, 946, 70-76.

55. A. Podgoršek, J. Jacquemin, A. A. H. Pádua and M. F. Costa Gomes, Chem. Rev., 2016, 116, 60756106.

56. P. Navia, J. Troncoso and L. Romani, J. Chem. Eng. Data, 2007, 52, 1369-1374. 
57. A. Podgoršek, A. S. Pensado, C. C. Santini, M. F. Costa Gomes and A. A. H. Pádua, J. Phys. Chem. C, 2013, 117, 3537-3547.

58. J. B. Miller, J. H. Walton and C. M. Roland, Macromolecules, 1993, 26, 5602-5610.

59. B. Nagasaka, T. Eguchi, H. Nakayama, N. Nakamura and Y. Ito, Radiat. Phys. Chem., 2000, 58, 581585.

60. J. Weber, J. Schmidt, A. Thomas and W. Böhlmann, Langmuir, 2010, 26, 15650-15656.

61. J. Demarquay and J. Fraissard, Chem. Phys. Lett., 1987, 136, 314-318.

62. P. J. Barrie and J. Klinowski, Prog. Nucl. Mag. Res. Sp., 1992, 24, 91-108.

63. Y.-H. Lim and A. D. King, Jr., J. Phys. Chem., 1993, 97, 12173-12177.

64. J. H. Walton, J. B. Miller and C. M. Roland, Appl. Magn. Reson., 1995, 8, 535-547.

65. F. Castiglione, R. Simonutti, M. Mauri and A. Mele, J. Phys. Chem. Lett., 2013, 4, 1608-1612.

66. P. Morgado, K. Shimizu, J. M. S. S. Esperança, P. M. Reis, L. P. N. Rebelo, J. N. Canongia Lopes and E. J. M. Filipe, J. Phys. Chem. Lett., 2013, 4, 2758-2762.

67. T. Ito and J. Fraissard, J. Chem. Phys., 1982, 76, 5225-5229.

68. G. Saielli, A. Bagno, F. Castiglione, R. Simonutti, M. Mauri and A. Mele, J. Phys. Chem. B, 2014, 118, 13963-13968.

69. D. Frezzato and G. Saielli, J. Phys. Chem. B, 2016, 120, 2578-2585.

70. M. H. Cohen and G. S. Grest, Phys. Rev. B, 1979, 20, 1077-1098.

71. T. G. Fox, Jr. and P. J. Flory, J. Appl. Phys., 1950, 21, 581-591.

72. W. Beichel, Y. Yu, G. Dlubek, R. Krause-Rehberg, J. Pionteck, D. Pfefferkorn, S. Bulut, D. Bejan, C. Friedrich and I. Krossing, Phys. Chem. Chem. Phys., 2013, 15, 8821-8830.

73. M. Forsyth, P. Meakin, D. R. MacFarlane and A. J. Hill, J. Phys.: Condens. Matter, 1995, 7, 76017617.

74. M. S. Shannon, J. M. Tedstone, S. P. O. Danielsen, M. S. Hindman, A. C. Irvin and J. E. Bara, Ind. Eng. Chem. Res., 2012, 51, 5565-5576.

75. M. S. Syamala, R. J. Cross and M. Saunders, J. Am. Chem. Soc., 2002, 124, 6216-6219.

76. M. Y. Lui, L. Crowhurst, J. P. Hallett, P. A. Hunt, H. Neidermeyer and T. Welton, Chem. Sci., 2011, 2, 1491-1496.

77. D. K. Singh, S. Cha, D. Nam, H. Cheong, S.-W. Joo and D. Kim, ChemPhysChem, 2016, 17, 3040-3046.

78. I. V. Voroshylova, E. S. C. Ferreira, M. Malček, R. Costa, C. M. Pereira and M. N. D. S. Cordeiro, Phys. Chem. Chem. Phys., 2018, 20, 14899-14918.

79. G. Saielli, J. Phys. Chem. B, 2016, 120, 2569-2577.

80. M. Luhmer and K. Bartik, J. Phys. Chem. A, 1997, 101, 5278-5283.

81. P. Morgado, R. Bonifácio, L. F. G. Martins and E. J. M. Filipe, J. Phys. Chem. B, 2013, 117, 9014-9024.

82. H. Yuan, S. Murad, C. J. Jameson and J. D. Olson, J. Phys. Chem. C, 2007, 111, 15771-15783.

83. M. Brüssel, M. Brehm, A. S. Pensado, F. Malberg, M. Ramzan, A. Stark and B. Kirchner, Phys. Chem. Chem. Phys., 2012, 14, 13204-13215. 